\title{
Review
}

\section{The Flavonoid Biosynthesis Network in Plants}

\author{
Weixin Liu ${ }^{1,2} \mathbb{D}$, Yi Feng ${ }^{1,2}$, Suhang $\mathrm{Yu}^{1,2}$, Zhengqi Fan ${ }^{1,2}$, Xinlei $\mathrm{Li}^{1,2}$, Jiyuan $\mathrm{Li}^{1,2, *}$ and Hengfu Yin ${ }^{1,2, *(\mathbb{0})}$ \\ 1 State Key Laboratory of Tree Genetics and Breeding, Research Institute of Subtropical Forestry, Chinese \\ Academy of Forestry, Hangzhou 311400, China; 1wx060624@163.com (W.L.); fy11071107@163.com (Y.F.); \\ yusuhang819@163.com (S.Y.); fzq_76@126.com (Z.F.); lixinlei2020@163.com (X.L.) \\ 2 Key Laboratory of Forest Genetics and Breeding, Research Institute of Subtropical Forestry, Chinese Academy \\ of Forestry, Hangzhou 311400, China \\ * Correspondence: jiyuan_li@126.com (J.L.); hfyin@sibs.ac.cn (H.Y.); Tel.: +86-571-6334-6372 (J.L.)
}

Citation: Liu, W.; Feng, Y.; Yu, S.;

Fan, Z.; Li, X.; Li, J.; Yin, H. The

Flavonoid Biosynthesis Network in Plants. Int. J. Mol. Sci. 2021, 22, 12824. https://doi.org/10.3390/

ijms222312824

Academic Editor: Guido R. M. M. Haenen

Received: 21 October 2021

Accepted: 18 November 2021

Published: 26 November 2021

Publisher's Note: MDPI stays neutral with regard to jurisdictional claims in published maps and institutional affiliations.

Copyright: (c) 2021 by the authors. Licensee MDPI, Basel, Switzerland. This article is an open access article distributed under the terms and conditions of the Creative Commons Attribution (CC BY) license (https:/ / creativecommons.org/licenses/by/ $4.0 /)$.

\begin{abstract}
Flavonoids are an important class of secondary metabolites widely found in plants, contributing to plant growth and development and having prominent applications in food and medicine. The biosynthesis of flavonoids has long been the focus of intense research in plant biology. Flavonoids are derived from the phenylpropanoid metabolic pathway, and have a basic structure that comprises a C15 benzene ring structure of C6-C3-C6. Over recent decades, a considerable number of studies have been directed at elucidating the mechanisms involved in flavonoid biosynthesis in plants. In this review, we systematically summarize the flavonoid biosynthetic pathway. We further assemble an exhaustive map of flavonoid biosynthesis in plants comprising eight branches (stilbene, aurone, flavone, isoflavone, flavonol, phlobaphene, proanthocyanidin, and anthocyanin biosynthesis) and four important intermediate metabolites (chalcone, flavanone, dihydroflavonol, and leucoanthocyanidin). This review affords a comprehensive overview of the current knowledge regarding flavonoid biosynthesis, and provides the theoretical basis for further elucidating the pathways involved in the biosynthesis of flavonoids, which will aid in better understanding their functions and potential uses.
\end{abstract}

Keywords: flavonoids; biosynthesis; molecular structure; biosynthetic enzyme; gene regulation

\section{Introduction}

Flavonoids comprise a group of phenylpropanoids that, as water-soluble pigments, are stored in the vacuoles of plant cells [1]. Except for stilbenes (a class of flavonoids), which has a C6-C2-C6 structure (Figure 1), the basic structure of flavonoids consists of a C6-C3-C6 carbon skeleton (Figure 1) comprising two 6-carbon benzene rings (rings $\mathrm{A}$ and B) linked by a 3-carbon heterocyclic ring (ring C) [2]. Flavonoids can be classified into 12 subgroups-chalcones, stilbenes, aurones, flavanones, flavones, isoflavones, phlobaphenes, dihydroflavonols, flavonols, leucoanthocyanidins, proanthocyanidins, and anthocyanins (Figure 1) [3,4] - based on the degree of oxidation of the heterocyclic ring and the number of hydroxyl or methyl groups on the benzene ring. At the same time, various modifications (glycosylation, acylation, and others) and molecular polymerization lead to the formation of a large number of flavonoid compounds $[5,6]$. To date, more than 9000 plant flavonoids have been isolated and identified [7].

Some flavonoids play an important role in plant development and defense. Flavonoids constitute one of the main pigments in plants, such as anthocyanins (red, orange, blue, and purple pigments); chalcones and aurones (yellow pigments); and flavonols and flavones (white and pale-yellow pigments), which impart on plants a wide variety of colors [8]. Flavonoids, as phytoalexins or antioxidants, have reactive oxygen species (ROS) scavenging ability [9] and protect plants against damage from biotic and abiotic stresses, including UV irradiation, cold stress, pathogen infection, and insect feeding [10-12]. In plants, flavonoids can also act as signaling molecules, attracting insects for pollination and participating in auxin metabolism [13]. Plant flavonoids also have widespread use in daily life, such 
as for food and medicinal purposes. For instance, anthocyanins and proanthocyanidins are important edible pigments and taste-regulating components in food and wine [4], while plant flavonoids, administered as active ingredients, can help delay the aging of the nervous system, immune organs, reproductive system, liver, and skin, and also contribute to the prevention of osteoporosis, cardiovascular disease, Alzheimer's disease, and breast cancer [14-16].

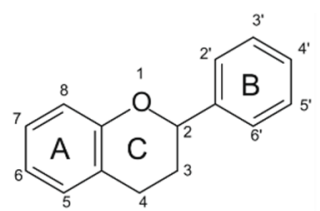

General structure of flavonoid<smiles>O=C(/C=C/c1ccccc1)c1ccccc1</smiles>

Chalcone<smiles>O=C1CC(c2ccccc2)Oc2ccccc21</smiles>

Flavanone<smiles>O=C1c2ccccc2OC(c2ccccc2)C1O</smiles>

Dihydroflavonol (Flavanonol)<smiles>OC1c2ccccc2OC(c2ccccc2)C1O</smiles>

Leucoanthocyanidin (Flavan-3,4-ol)<smiles>O=c1cc(-c2ccccc2)oc2ccccc12</smiles>

Flavone<smiles>O=c1c(O)c(-c2ccccc2)oc2ccccc12</smiles>

Flavonol<smiles>C(=C/c1ccccc1)\c1ccccc1</smiles>

Stilbene<smiles>O=c1c(-c2ccccc2)coc2ccccc12</smiles>

Isoflavone<smiles></smiles>

Anthocyanin<smiles>O=C1/C(=C/c2ccccc2)Oc2ccccc21</smiles>

Aurone<smiles>OC1CC(c2ccccc2)Oc2ccccc21</smiles>

Phlobaphene

(Flavan-4-ol)<smiles>OC1Cc2ccccc2OC1c1ccccc1</smiles>

Proanthocyanidin (Flavan-3-ol)

Figure 1. General structure of flavonoids.

Flavonoids have long been a major focus of research into secondary metabolism. On PubMed, performing a search using 'flavonoid' as a search term retrieves more than 10,000 articles in both 2019 and 2020. Recent decades have witnessed a considerable renewed interest in flavonoid biosynthesis in plants. In this review, we present a systematic summary of what is known of the flavonoid biosynthetic pathway in plants, presenting a model of flavonoid biosynthesis that includes eight branches and four intermediate metabolites (Figure 2), thereby providing a theoretical basis for the genetic improvement of flavonoid metabolism as well as improving our understanding of their functions and potential uses. 


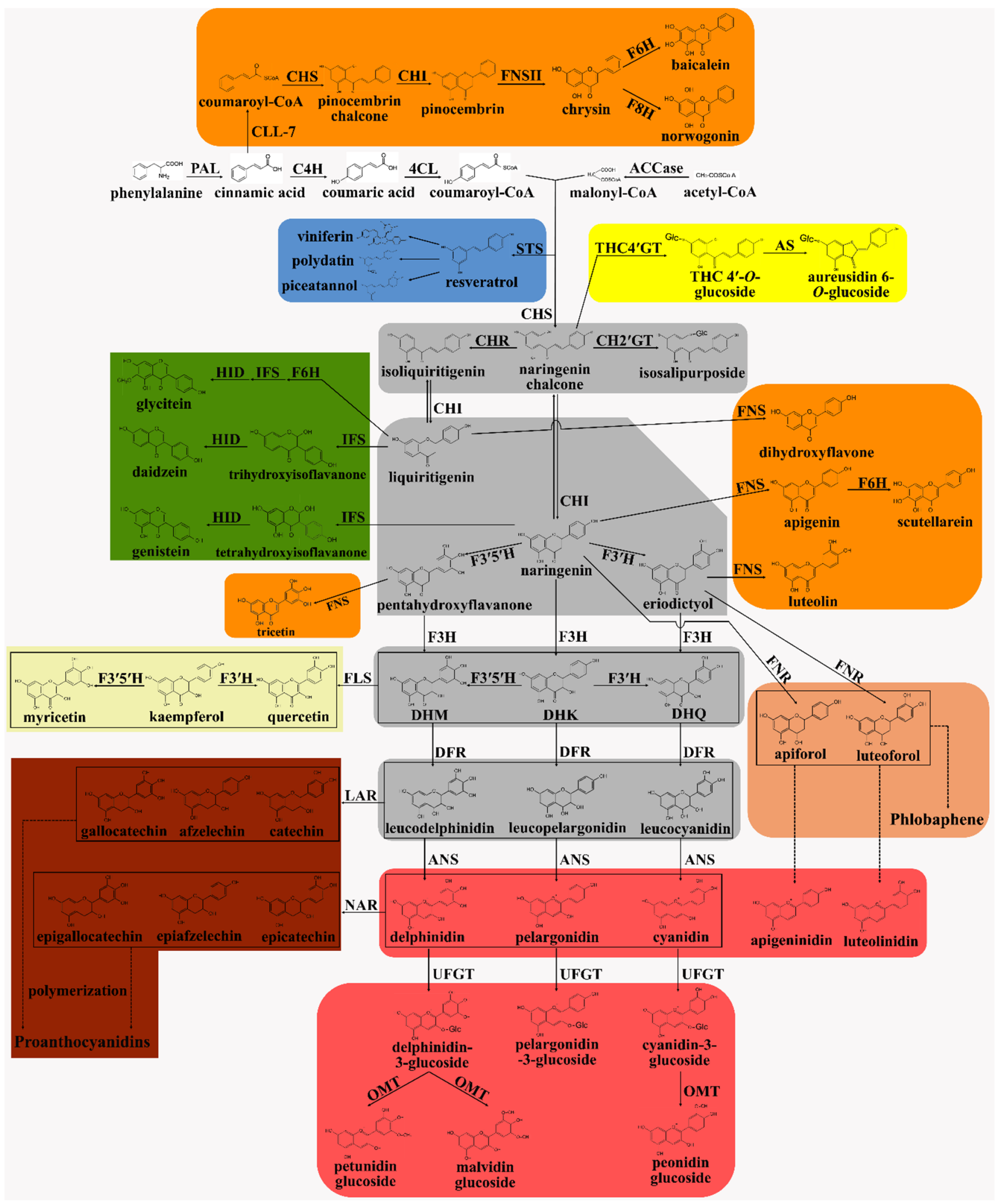

Figure 2. The flavonoid biosynthetic pathway in plants contains eight branches (represented by the eight colored boxes) and four important intermediate metabolites (gray boxes). The enzyme names and flavonoid compounds are abbreviated as follows: PAL, phenylalanine ammonia lyase; $\mathrm{C} 4 \mathrm{H}$, cinnamic acid 4-hydroxylase; 4CL, 4-coumarate: CoA ligase; ACCase, acetyl-CoA carboxylase; STS, stilbene synthase; $\mathrm{CHS}$, chalcone synthase; $\mathrm{CHR}$, chalcone reductase; $\mathrm{CH2}$ 'GT, chalcone 2'-glucosyltransferase; $\mathrm{CH} 4^{\prime} \mathrm{GT}$, chalcone 4'-O-glucosyltransferase; AS, aureusidin synthase; $\mathrm{CHI}$, chalcone isomerase; FNS, flavone synthase; CLL-7, cinnamate-CoA ligase; F6H, flavonoid 6-hydroxylase; F8H, flavonoid 8-hydroxylase; IFS, isoflavone synthase; HID, 2-hydroxyisoflavanone dehydratase; FNR, flavanone 4-reductase; F3H, flavanone 3-hydroxylase; 
F3'5' $\mathrm{H}$, flavanone 3',5'-hydroxylase; DHK, dihydrokaempferol; DHQ, dihydroquercetin; DHM, dihydromyricetin; FLS, flavonol synthase; DFR, dihydroflavonol 4-reductase; ANS, anthocyanidin synthase; UFGT, UDP-glucose flavonoid 3-Oglucosyltransferase; OMT, O-methyl transferases; LAR, leucoanthocyanidin reductase; ANR, anthocyanidin reductase.

\section{Flavonoid Biosynthesis in Plants}

\subsection{The General Phenylpropanoid Pathway}

Flavonoids are generated from phenylalanine through the phenylpropanoid pathway, while phenylalanine is synthesized via the shikimate pathway [17]. The first three steps in the phenylpropanoid pathway are referred to as the general phenylpropanoid pathway [1]. In this pathway, phenylalanine, an aromatic amino acid, is converted to $p$-coumaroyl-CoA through the activity of phenylalanine ammonia lyase (PAL), cinnamic acid 4-hydroxylase $(\mathrm{C} 4 \mathrm{H})$, and 4-coumarate: CoA ligase (4CL). PAL catalyzes the first committed step in the general phenylpropanoid pathway, namely, the deamination of phenylalanine to trans-cinnamic acid [18]. Additionally, PAL plays a key role in mediating carbon flux from primary to secondary metabolism in plants [19]. PAL activity has been linked to the concentrations of anthocyanins and other phenolic compounds in strawberry fruit [20] while StlA, a Photorhabdus luminescens PAL-encoding gene, was shown to be involved in the production of a stilbene antibiotic [18]. The second step in the general phenylpropanoid pathway involves the activity of $\mathrm{C} 4 \mathrm{H}$, a cytochrome $\mathrm{P} 450$ monooxygenase in plants, which catalyzes the hydroxylation of trans-cinnamic acid to generate $p$-coumaric acid. This is also the first oxidation reaction in the flavonoid synthesis pathway [21]. In Populus trichocarpa and Arabidopsis thaliana, the expression level of $C 4 H$ has been associated with the content of lignin, an important phenylpropanoid metabolite [1] In the third step of the general phenylpropanoid pathway, 4CL catalyzes the formation of $p$-coumaroyl-CoA by the addition of a co-enzyme A (CoA) unit to $p$-coumaric acid. In plants, the $4 C L$ gene usually exists as a family the members of which mostly display substrate specificity. Of the four 4CL genes in A. thaliana, At4CL1, At4CL2, and At4CL4 are involved in lignin biosynthesis, while At4CL3 has a role in flavonoid metabolism [22]. In plants, the activity of $4 \mathrm{CL}$ is positively correlated with the anthocyanin and flavonol content in response to stress [23], while PAL, C4H, and $4 C L$ are often coordinately expressed [24]. The general phenylpropanoid pathway is common to all the downstream metabolites, such as flavonoids and lignin. In this review, we focus on the flavonoid biosynthetic pathway, and present a model that includes eight branches-the biosynthesis of stilbenes, aurones, flavones, isoflavones, flavonols, phlobaphenes, proanthocyanidins, and anthocyanins-and four important intermediate metabolites, namely, chalcones, flavanones, dihydroflavonols, and leucoanthocyanidins (Figure 2).

\subsection{Chalcone: The First Key Intermediate Metabolite in Flavonoid Biosynthesis}

The entry of $p$-coumaroyl-CoA into the flavonoid biosynthesis pathway represents the start of the synthesis of specific flavonoids, which begins with chalcone formation [2]. One molecule of $p$-coumaroyl-CoA and three molecules of malonyl-COA, derived from acetyl-CoA via the activity of acetyl-CoA carboxylase (ACCase), generate naringenin chalcone $\left(4,2^{\prime}, 4^{\prime}, 6^{\prime}\right.$-tetrahydroxychalcone [THC] [chalcone]) through the action of chalcone synthase (CHS) [25]. CHS, a polyketide synthase, is the key and first rate-limiting enzyme in the flavonoid biosynthetic pathway [26,27]. In tomato (Solanum lycopersicum), RNA interference (RNAi)-mediated suppression of $\mathrm{CHS}$ leads to a reduction in total flavonoid levels [28]. Chalcone reductase (CHR), an aldo-keto reductase superfamily member, acts on an intermediate of the CHS reaction, catalyzing its C- $6^{\prime}$ dehydroxylation, yielding isoliquiritigenin (4,2', $4^{\prime}$-trihydroxychalcone [deoxychalcone]) [29]. Overexpressing the CHR1 gene from Lotus japonicus in petunia leads to the formation of isoliquiritigenin and a decrease in anthocyanin content [30]. Because THC is readily converted to a colorless naringenin under the action of chalcone isomerase (CHI) or through spontaneous isomerization, it is 
frequently converted to the more stable THC $2^{\prime}$-glucoside (isosalipurposide [ISP]) under the action of chalcone $2^{\prime}$-glucosyltransferase $\left(\mathrm{CH} 2^{\prime} \mathrm{GT}\right)$ in plant vacuoles [31,32]. Differences in $\mathrm{CH} 2^{\prime} \mathrm{GT}$ gene expression or enzymatic activity might account for the difference in ISP content in the petals of different varieties of yellow carnation [33]. Chalcone is the first key intermediate product in the flavonoid metabolic pathway, providing a basic skeleton for downstream flavonoid synthesis. Chalcone (THC, isoliquiritigenin, and ISP, among others) is also an important yellow pigment in plants [31].

\subsection{Stilbene Biosynthesis: The First Branch of the Flavonoid Biosynthesis Pathway}

Stilbene synthase (STS) also uses $p$-coumaroyl-CoA and malonyl-CoA as substrates and catalyzes the formation of the stilbene backbone, such as resveratrol [34,35]. The stilbene pathway is the first branch of the flavonoid biosynthesis pathway and exists only in a few plants, such as grapevine, pine, sorghum, and peanut [36,37]. STS, a member of the type III polyketide synthase family, is the first and key enzyme in stilbene biosynthesis, and is closely related to, and evolved from, CHS [34]. However, STS generates a compound with a different $\mathrm{C} 14$ backbone (C6-C2-C6) along with the release of 4 carbon dioxide $\left(\mathrm{CO}_{2}\right)$ molecules, while $\mathrm{CHS}$ catalyzes the formation of $\mathrm{C} 15$ skeletons (C6-C3-C6), with only 3 molecules of $\mathrm{CO}_{2}$ being released [38]. In Vitis amurensis calli, the overexpression of Picea jezoensis PjSTS1a, PjSTS2, and PjSTS3 greatly increases the total stilbene content [39]. Most plant stilbenes are derivatives of the basic unit transresveratrol (3,5,4'-trihydroxy-trans-stilbene) that has undergone various modifications, such as isomerization, glycosylation, methylation, oligomerization, and prenylation [36]. Trans-resveratrol can be converted to polydatin, pterostilbene, and piceatannol by glycosylation, methylation, and hydroxylation, respectively [35]. In peanuts, the major prenylated stilbene compounds are trans-3'-(3-methyl-2-butenyl)-resveratrol and transarachidin-1/2/3 [40]. Viniferin and cis-stilbene are derived from the oligomerization and isomerization of trans-resveratrol, respectively [36,41].

\subsection{Aurone Biosynthesis: The Bright Yellow Pigment Pathway}

Aurones, important yellow pigments in plants, comprise a class of flavonoids derived from chalcone [42]. Aurone pigments produce brighter yellow coloration than chalcones and are responsible for the golden color in some popular ornamental plants [31]. Aurones are found in relatively few plant species, such as snapdragon, sunflowers, and coreopsis [42,43]. THC is the direct substrate for aurone biosynthesis [44]. First, chalcone $4^{\prime}$-O-glucosyltransferase $\left(\mathrm{CH}^{\prime} \mathrm{GT}\right)$ catalyzes the formation of THC $4^{\prime}$-O-glucoside from THC in the plant cytoplasm. The former is then transferred to the vacuole and converted to aureusidin 6-O-glucoside (aurone) by the action of aureusidin synthase (AS) [45,46]. AS can also catalyze the formation of aureusidin directly from THC; aureusidin and its glycosides are the main pigments in the yellow petal of Antirrhinum majus and Dahlia variabilis [47]. $2^{\prime}, 4^{\prime}, 6^{\prime}, 3,4-\mathrm{Pentahydroxychalcone} \mathrm{(PHC,} \mathrm{a} \mathrm{type} \mathrm{of} \mathrm{chalcone)} \mathrm{can} \mathrm{also} \mathrm{be} \mathrm{con-}$ verted into aurones (bracteatin and bracteatin 6-O-glucoside) by $\mathrm{CH} 4^{\prime} \mathrm{GT}$ and/or AS [31,47]. $\mathrm{CH} 4^{\prime} \mathrm{GT}$ and $\mathrm{CHI}$ can both use chalcone as a substrate, and $4^{\prime}$-gulcosylation by $\mathrm{CH} 4^{\prime} \mathrm{GT}$ not only provides a direct precursor for aurone synthesis, but also inhibits the isomerization activity of $\mathrm{CHI}$ by repressing key interactions between $\mathrm{CHI}$ and the $4^{\prime}$-hydroxy group of chalcones [48]. AS, a homolog of plant polyphenol oxidase (PPO), catalyzes the 4-monohydroxylation or 3,4-dihydroxylation of ring B to produce aurone, followed by oxidative cyclization by oxygenation [49]. Both in Ipomoea nil [50] and Torenia [45], the co-overexpression of the $A m C H 4^{\prime} G T$ and AmAS1 genes leads to the accumulation of aurone 6-O-glucoside. Furthermore, various classical substitution patterns, such as hydroxylation, methoxylation, and glycosylation, lead to the formation of a series of aurone compounds, with over 100 structures having been reported to date [48]. 


\subsection{Flavanones: The Central Branch Point in the Flavonoid Biosynthesis Pathway}

$\mathrm{CHI}$ catalyzes the intramolecular cyclization of chalcones to form flavanones in the cytoplasm, resulting in the formation of the heterocyclic ring $C$ in the flavonoid pathway [2,51]. In general, CHIs can be classified into two types in plants according to the substrate utilized [52]. Type I CHIs, ubiquitous in vascular plants, are responsible for the conversion of THC into naringenin [53]. Type II CHIs are found primarily in leguminous plants and can utilize either THC or isoliquiritigenin to generate naringenin and liquiritigenin [1]. Apart from these two types, two other types of CHI exist (type III and type IV), which retain the catalytic activity of the $\mathrm{CHI}$ fold but not chalcone cyclization activity [54]. In bacteria, some CHI-like enzymes catalyze a reversible reaction in the flavonoid pathway that converts flavanones to chalcones [8]. $\mathrm{CHI}$ is the second key rate-limiting enzyme in the flavonoid biosynthesis pathway [52]. The expression level of $\mathrm{CHI}$ was found to be positively correlated with flavonoid content in A. thaliana [55]. In both Dracaena cambodiana and tobacco, the overexpression of DcCHI1 or DcCHI4 leads to increased flavonoid accumulation [53]. In transgenic tobacco plants, RNAi-mediated suppression of $\mathrm{CHI}$ enhances the level of chalcone in pollen [56]. Furthermore, naringenin can be converted to eriodictyol and pentahydroxyflavanone (two flavanones) under the action of flavanone $3^{\prime}$-hydroxylase $\left(\mathrm{F} 3^{\prime} \mathrm{H}\right)$ and flavanone $3^{\prime}, 5^{\prime}$-hydroxylase $\left(\mathrm{F}^{\prime} 5^{\prime} \mathrm{H}\right)$ at position $\mathrm{C}-3$ and / or $\mathrm{C}-5$ of ring $\mathrm{B}$ [8]. Flavanones (naringenin, liquiritigenin, pentahydroxyflavanone, and eriodictyol) represent the central branch point in the flavonoid biosynthesis pathway, acting as common substrates for the flavone, isoflavone, and phlobaphene branches, as well as the downstream flavonoid pathway [51,57].

\subsection{Flavone Biosynthesis}

Flavone biosynthesis is an important branch of the flavonoid pathway in all higher plants. Flavones are produced from flavanones by flavone synthase (FNS); for instance, naringenin, liquiritigenin, eriodictyol, and pentahydroxyflavanone can be converted to apigenin, dihydroxyflavone, luteolin, and tricetin, respectively [58-60]. FNS catalyzes the formation of a double bond between position C-2 and C-3 of ring $C$ in flavanones and can be divided into two classes-FNSI and FNSII [61]. FNSIs are soluble 2-oxoglutarate- and $\mathrm{Fe}^{2+}$ dependent dioxygenases mainly found in members of the Apiaceae [62]. Meanwhile, FNSII members belong to the NADPH- and oxygen-dependent cytochrome P450 membranebound monooxygenases and are widely distributed in higher plants $[63,64]$. FNS is the key enzyme in flavone formation. Morus notabilis FNSI can use both naringenin and eriodictyol as substrates to generate the corresponding flavones [62]. In A. thaliana, the overexpression of Pohlia nutans FNSI results in apigenin accumulation [65]. The expression levels of FNSII were reported to be consistent with flavone accumulation patterns in the flower buds of Lonicera japonica [61]. In Medicago truncatula, meanwhile, MtFNSII can act on flavanones, generating intermediate 2-hydroxyflavanones (instead of flavones), which are then further converted into flavones [66]. Flavanones can also be converted to $C$-glycosyl flavones (Dong and Lin, 2020). Naringenin and eriodictyol are converted to apigenin C-glycosides and luteolin C-glycosides under the action of flavanone-2-hydroxylase (F2H), $C$-glycosyltransferase (CGT), and dehydratase [67].

Scutellaria baicalensis is a traditional medicinal plant in China and is rich in flavones such as wogonin and baicalein [17]. There are two flavone synthetic pathways in S. baicalensis, namely, the general flavone pathway, which is active in aerial parts; and a root-specific flavone pathway [68]), which evolved from the former [69]. In this pathway, cinnamic acid is first directly converted to cinnamoyl-CoA by cinnamate-CoA ligase (SbCLL-7) independently of $\mathrm{C} 4 \mathrm{H}$ and $4 \mathrm{CL}$ enzyme activity [70]. Subsequently, cinnamoyl-CoA is continuously acted on by CHS, CHI, and FNSII to produce chrysin, a root-specific flavone [69]. Chrysin can further be converted to baicalein and norwogonin (two rootspecific flavones) under the catalysis of respectively flavonoid 6-hydroxylase $(\mathrm{F} 6 \mathrm{H})$ and flavonoid 8-hydroxylase (F8H), two CYP450 enzymes [71]. Norwogonin can also be converted to other root-specific flavones-wogonin, isowogonin, and moslosooflavone- 
under the activity of O-methyl transferases (OMTs) [72]. Additionally, F6H can generate scutellarein from apigenin [70]. The above flavones can be further modified to generate additional flavone derivatives.

\subsection{Isoflavone Biosynthesis}

The isoflavone biosynthesis pathway is mainly distributed in leguminous plants [73]. Isoflavone synthase (IFS) leads flavanone to the isoflavone pathway [74] and appears to be able to use both naringenin and liquiritigenin as substrates to generate 2-hydroxy2,3-dihydrogenistein and 2,7,4'-trihydroxyisoflavanone, respectively [75,76]. These are further converted to isoflavone genistein and daidzein under the action of hydroxyisoflavanone dehydratase (HID) [77]. Liquiritigenin can also be first converted to $6,7,4^{\prime}-$ trihydroxyflavanone by $\mathrm{F} 6 \mathrm{H}$, and then to glycitein (an isoflavone) through the catalytic activities of IFS, HID, and isoflavanone O-methyl transferase (IOMT) [78]. IFS and HID catalyze two reactions to produce isoflavone, that is, the formation of a double bond between positions C-2 and C-3 of ring C and a shift of ring B from position C-2 to C-3 of ring $C[79,80]$. IFS, a cytochrome $P 450$ hydroxylase, is the first and key enzyme in the isoflavone biosynthesis pathway [81]. The overexpression of Glycine max IFS in Allium cepa led to the accumulation of the isoflavone genistein in in vitro tissues [82]. Knocking out the expression of the IFS1 gene using CRISPR/Cas9 led to a significant reduction in the levels of isoflavones such as genistein [58]. Various modifications further generate specific isoflavones. Daidzein is converted to puerarin or formononetin by a specific glycosyltransferase (GT) or IOMT $[79,83]$. Malonyltransferase (MT) can act on isoflavones (genistein, daidzein, and glycitein) to generate the corresponding malonyl-isoflavones (malonylgenistein, malonyldaidzein, and malonylglycitein) [80]. Moreover, the successive enzymatic reactions catalyzed by IOMT, isoflavone reductase (IFR), isoflavone $2^{\prime}$-hydroxylase (I2 $\left.{ }^{\prime} \mathrm{H}\right)$ or isoflavone $3^{\prime}$-hydroxylase $\left(\mathrm{I}^{\prime} \mathrm{H}\right)$, vestitone reductase (VR), pterocarpan synthase (PTS), and $7,2^{\prime}$-dihydroxy- $4^{\prime}$-methoxyisoflavanol dehydratase (DMID) lead to the accumulation of isoflavonoids such as maackiain and pterocarpan $[1,84,85]$.

\subsection{Phlobaphene Biosynthesis}

Besides flavones and isoflavones, the biosynthesis of phlobaphenes also uses flavanones as substrates [86]. Phlobaphenes are reddish insoluble pigments in plants [87] and are predominantly found in seed pericarp, cob-glumes, tassel glumes, husk, and floral structures of plants such as maize and sorghum [88-90]. Flavanone 4-reductase (FNR) acts on flavanones (naringenin and eriodictyol) to form the corresponding flanvan-4-ols (apiforol and luteoforol), which are the immediate precursors of pholbaphenes [91,92]. Apiforol and luteoforol are then further polymerized to generate phlobaphenes [57]. FNR is a NADPH-dependent reductase and drives the substitution of an oxygen with a hydroxyl group at position C-4 of ring C [89]. FNR is also a dihydroflavonol 4-reductase (DFR)-like enzyme, and can convert dihydroflavonol to leucoanthocyanidin [93]. In maize, DFR and FNR correspond to the same enzyme [91]. The inhibition of flavanone 3-hydroxylase (F3H) activity promotes the conversion of flavanone to flavan-4-ol through the catalytic activity of FNR in Sinningia cardinalis and Zea mays [94].

\subsection{Dihydroflavonol: A Key Branch Point in the Flavonoid Biosynthesis Pathway}

Dihydroflavonol (or flavanonol) is an important intermediate metabolite and a key branch point in the flavonoid biosynthesis pathway. Dihydroflavonol is generated from flavanone under the catalysis of $\mathrm{F} 3 \mathrm{H}$ and is the common precursor for flavonol, anthocyanin, and proanthocyanin $[95,96]$. F3H acts on naringenin, eriodictyol, and pentahydroxyflavanone to form the corresponding dihydroflavonols, namely, dihydrokaempferol (DHK), dihydroquercetin (DHQ), and dihydromyricetin (DHM) $[97,98]$. Moreover, DHK can be converted to DHQ by F3' $\mathrm{H}$ and $\mathrm{DHK}$, while DHQ can generate DHM under the action of $\mathrm{F}^{\prime} 5^{\prime} \mathrm{H}[51]$. 
F3H, a FeII/2-oxoglutarate-dependent dioxygenase, catalyzes the dydroxylation of flavonones at position C-3 and is the key enzyme in dihydroflavonol synthesis [99]. Because flavanones are also the substrates in the flavone, isoflavone, and phlobaphene biosynthetic pathways, F3H competes with FNS, IFS, and FNR for these common substrates [98]. The overexpression of $F 3 H$ leads to the generation of DHK in tobacco and yeast [100]. In Silybum marianum, F3H was shown to catalyze the synthesis of taxifolin (DHQ) from eriodictyol [101], while the expression of $A g F 3 H$ was significantly positively correlated with DHM content in different tissues of Ampelopsis grossedentata [102].

$\mathrm{F}^{\prime} \mathrm{H}$ and $\mathrm{F}^{\prime} 5^{\prime} \mathrm{H}$, both cytochrome P450 enzymes, catalyze the hydroxylation of flavonoids at position $\mathrm{C}-3^{\prime}$ or $\mathrm{C}-3^{\prime}$ and $\mathrm{C}-5^{\prime}$ of ring $\mathrm{B}$, respectively, so as to the formation of substrates of different pathways $[8,103]$. F3 $3^{\prime} \mathrm{H}$ and $\mathrm{F}^{\prime} 5^{\prime} \mathrm{H}$ generate flavanones with differing degrees of hydroxylation, resulting in naringenin, eriodictyol, and pentahydroxyflavanone entering different flavone synthetic pathways [60]. F3' $\mathrm{H}$ catalyzes the production of $\mathrm{DHQ}$, which is the synthetic precursor of cyanidin in the anthocyanidin pathway and quercetin in the flavonol pathway [104]. DHM, synthesized by $\mathrm{F}^{\prime} 5^{\prime} \mathrm{H}$, is the direct precursor of delphinidin in the anthocyanidin pathway and myricetin in the flavonol pathway, while DHK can be converted to pelargonidin (an anthocyanidin) and kaempferol (a flavonol) [3,98]. Thus, $\mathrm{F}^{\prime} \mathrm{H}$ and $\mathrm{F}^{\prime} 5^{\prime} \mathrm{H}$ are the determinants of flavonoid composition in many plants and the key enzymes in flavonoid biosynthesis. The ectopic expression of apple $\mathrm{F}^{\prime} \mathrm{H}$ genes increases the levels of quercetin and cyanidin in Arabidopsis and tobacco [105]. Meanwhile, delphinidin levels are decreased while those of cyanidin are increased in a natural Glycine soja $f^{\prime} 5^{\prime} h$ mutant [106].

\subsection{Flavonol Biosynthesis}

Flavonols are flavonoid metabolites that are hydroxylated at position C-3 of ring C [51]. Their C-3 position is highly prone to glycosidation; accordingly, they often exist in plant cells in glycosidated forms [98]. The dihydroflavonols DHK, DHQ, and DHM are respectively converted to the flavonols kaempferol, quercetin, and myricetin by flavonol synthase (FLS) [107]. F3' $\mathrm{H}$ can also catalyze the conversion of kaempferol to quercetin, while $\mathrm{F}^{\prime} 5^{\prime} \mathrm{H}$ activity generates myricetin from kaempferol or quercetin [108]. Kaempferol, quercetin, and myricetin are further modified to various flavonol derivatives through the activities of enzymes such as methyl transferases, GTs, and acyltransferase (AT), among others [60,109]. FLS, a FeII/2-oxoglutarate-dependent dioxygenase, is the key and rate-limiting enzyme in the flavonol biosynthesis pathway [110] and catalyzes the desaturation of dihydroflavonol to form a C-2 and C-3 double bond in ring C [111]. The ectopic expression of Camellia sinensis $F L S a / b / c$ in tobacco promoted the accumulation of kaempferol and a decrease in anthocyanin content in flowers [112]. Meanwhile, the overexpression of FLS of Allium cepa in tobacco enhanced quercetin signals in the roots [113].

\subsection{Leucoanthocyanidin and Anthocyanin Biosynthesis}

DFR, a NADPH-dependent reductase, is the key enzyme in flavonoid metabolism in the anthocyanidin and proanthocyanidin pathway and catalyzes the formation of a hydroxyl group at position C-4 of ring C [114-116]. DFR catalyzes the reduction of dihydroflavonols, DHK, DHQ, and DHM to produce their respective leucoanthocyanidins (also known as flavan-3,4-ols or flavan-diols), leucopelargonidin, leucocyanidin, and leucodelphinidin [117]. Because DHK, DHQ, and DHM are very similar in structure, differing only in the numbers of hydroxyl groups on the B ring (which is not the site of enzymatic action), DFR can use all three as substrates in most plants [118]. In Vitis vinifera, DFR converts DHK to leucopelargonidin [119]. The overexpression of Brassica oleracea DRF1 was shown to promote anthocyanin accumulation, whereas the virus-induced silencing of the BoDRF1 gene elicited the opposite effect [120]. DFR and FLS compete for common dihydroflavonol substrates and DFR and FLS inhibit each other's transcription [121].

Leucoanthocyanidin is an important intermediate product in the flavonoid pathway and the direct synthetic precursor of anthocyanidin and proanthocyanidin. The colorless 
leucopelargonidin, leucocyanidin, and leucodelphinidin are transformed into the corresponding anthocyanidins (the colored pelargonidin, cyanidin, and delphinidin) under the catalysis of anthocyanidin synthase (ANS), also known as leucoanthocyanidin dioxygenase (LDOX) [122,123]. Like FLS, F3H, and FNSI, ANS/LDOX is also a FeII/2-oxoglutaratedependent dioxygenase, and catalyzes the dehydroxylation of C-4 and the formation of a double bond in ring $C[3,124]$. ANS overexpression in strawberry enhanced the anthocyanin concentration [125]. In plants, unstable anthocyanidins are converted to stable anthocyanins, namely, pelargonidin-3-glucoside, cyanidin-3-glucoside, and delphinidin-3glucoside, by UDP-glucose flavonoid 3-glucosyltransferase (UFGT) [126,127]. OMT can further catalyze the conversion of cyanidin-3-glucoside to peonidin glycoside and delpinidin3-glucoside to petunidin glycoside or malvidin glycoside [118,128]. The pelargonidin, cyanidin, peonidin, delphinidin, petunidin, and malvidin glycosides constitute six major categories of anthocyanins and their further modifications (acylation, glycosylation, and methylation) lead to the formation of various anthocyanins $[5,118,127]$.

In addition to the above-mentioned anthocyanins, a rare type of anthocyanin, 3deoxyanthocyanidin, also exists in plants [129]. The biosynthesis of 3-deoxyanthocyanidins is similar to that of the phlobaphenes, and they both use flavan-4-ols (luteoferol and apiferol) as substrates [130]. Luteoforol and apiferol are respectively transformed into 3-deoxyanthocyanidins (luteolinidin and apigeninidin) by an unknown enzyme, likely with anthocyanidin synthase-like activity [57,94]. Luteolinidin and apigeninidin are further converted into 3-deoxyanthocyanidin glycosides (3-deoxyanthocyanins) by GT [131] Unlike anthocyanidins, 3-deoxyanthocyanidins lack a hydroxyl group at position C-3 of ring $C$, giving them greater stability under temperature fluctuations as well as greater color stability [132,133]. In plants, 3-deoxyanthocyanidins mainly exist in the aglycone form, and not as 3-deoxyanthocyanins, whereas the anthocyanidins primarily exist in glycoside form (anthocyanins) [133]. 3-Deoxyanthocyanidins have been found in many plants, including sorghum and maize $[130,134]$; however, their biosynthetic pathway needs to be further analyzed.

\subsection{Proanthocyanidin Biosynthesis}

Proanthocyanidins, also known as condensed tannins, are an important type of flavonoid synthesized from leucoanthocyanidins and anthocyanidins. Leucoanthocyanidin reductase (LAR) converts leucoanthocyanidins, leucopelargonidin, leucocyanidin, and leucodelphinidin to trans-flavan-3-ols, afzelechin, catechin, and gallocatechin, respectively $[135,136]$. LAR, a NADPH-dependent reductase, drives the C-4 dehydroxylation of the $C$ ring [137]. Anthocyanidin reductase (ANR) can convert anthocyanidins, pelargonidin, cyanidin, and delphinidin, into the corresponding cis-flavan-3-ols, epiafzelechin, epicatechin, and epigallocatechin [138]. ANR is also a NADPH-dependent reductase and catalyzes the removal of a double bond at ring C [139]. Flavan-3-ols, trans-flavan-3-ols, and cis-flavan-3-ols are the basic proanthocyanidin units. Proanthocyanidins are synthesized via the polymerization (or condensation) of flavan-3-ols [140,141]. Colorless proanthocyanidins are transferred to plant vacuoles [142] and can be oxidized to generate colored tannins (yellow to brown) by polyphenol oxidase (PPO) [135]. LAR and ANR are the key and rate-limiting enzymes in proanthocyanidin biosynthesis. In Populus tomentosa, the overexpression of $L A R 3$ greatly increased the proanthocyanidin levels [143]. The ectopic expression of OvBAN, an ANR gene from Onobrychis viviaefolia, in alfalfa (Medicago sativa) promoted ANR enzyme activity and enhanced proanthocyanidin content [144]. Because they use the same substrates, a competitive relationship exists between the proanthocyanidin and anthocyanin biosynthesis pathways [145].

\section{Transcriptional Regulation of Flavonoid Biosynthesis in Plants}

Transcriptional control plays a central role in the modulation of flavonoid biosynthesis (Figure 3). The MBW complex, composed of MYB, bHLH, and WD40, is the main transcriptional regulator in flavonoid biosynthesis [146]. MYB transcription factors have a 
conserved MYB domain in the N-terminus that is required for DNA binding and interaction with other proteins [147]. MYB proteins can be divided into four groups-1R-MYB/MYBrelated, R2R3-MYB, 3R-MYB, and 4R-MYB-according to the number and position of MYB domain repeats [117]. Members of the R2R3-MYB group are mainly involved in regulating flavonoid metabolism [148]. The overexpression of AN4 (a R2R3-MYB-encoding gene) can enhance anthocyanin biosynthesis by promoting the expression of anthocyanin biosynthesis genes, such as CHS, CHI, F3H, and DFR [149]. In Cucumis sativus, the R2R3-MYB transcription factor CsMYB60 induced the expression of CsFLS and CsLAR by binding to their promoters, thereby promoting flavonol and proanthocyanidin biosynthesis [150]. MYB transcription factors also act as repressors in the regulation of flavonoid biosynthesis. For instance, in the apple (Malus domestica), MdMYB15L was reported to interact with MdbHLH33 and inhibit the promotion of the MdbHLH33-MYB-WD40 (MBW) complex, thereby also suppressing anthocyanin biosynthesis [151].

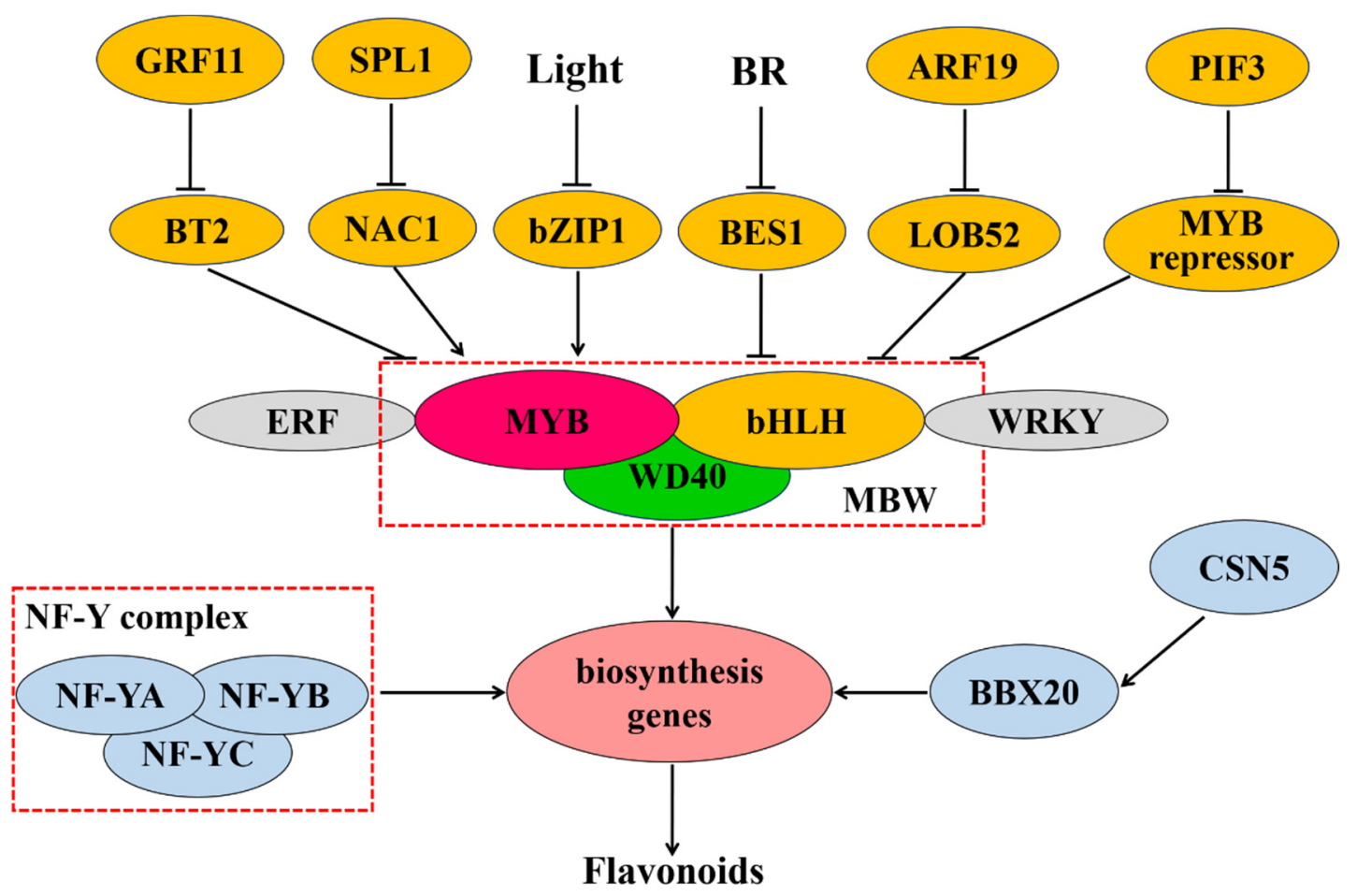

Figure 3. Transcriptional regulation of flavonoid biosynthesis in plants. Abbreviations are as follows: MYB, $v-m y b$ avian myeloblastosis viral oncogene homolog; bHLH, basic helix-loop-helix; NF-Y, nuclear factor Y; ERF, ethylene response factor; NAC, (NAM, ATAF, CUC); SPL, squamosa promoter binding protein-like; GRF, growth regulating factor; BT, $\mathrm{BTB} / \mathrm{TAZ}$; BBX, b-box protein; ARF, auxin response factor; LOB, lateral organ boundaries; BES1, BRI1-EMS-SUPPRESSOR 1; $\mathrm{BR}$, brassinosteroid. The red dashed box represents the protein complex: MBW complex is constituted of three class of transcription factors (TFs), MYB, bHLH and WD40, while NF-Y complex is composed of TFs NF-YA, NF-YB, and NF-YC. TFs next to each other represent interaction of proteins.

bHLH transcription factors have been shown to participate in the regulation of flavonoid biosynthesis. The transient expression of DhbHLH1 induces anthocyanin synthesis in the white petals of Dendrobium hybrids [152]. In Dianthus caryophyllus, meanwhile, the "red speckles and stripes on white petals" phenotype results from the local expression of $b H L H$, which promotes the expression of DFR and that of downstream enzymes in the anthocyanin biosynthetic pathway [153].

WD40, widely present in eukaryotic cells, contains multiple tandem repeats of a WD motif and interacts with other proteins through its WD domain [1]. Generally, WD40 does not directly bind to target gene promoters, forming instead a complex with MYB and bHLH in the regulation of flavonoid biosynthesis. The WD40 protein TTG1 regulated anthocyanin 
metabolism through MYB/bHLH/TTG1 complex [154]. Moreover, in tomato, the WD40 protein SIAN11 was shown to induce anthocyanin and proanthocyanidin biosynthesis and limit flavonol accumulation by repressing FLS expression [155].

Also in tomato, besides the MBW complex, the transcription factors NF-YA, NF-YB, and NF-YC can reportedly form a NF-Y protein complex that binds to the promoter of the CHS1 gene, thereby regulating flavonoid synthesis and affecting tomato peel color [25]. Additionally, the ethylene response factors Pp4ERF24 and Pp12ERF96, through interacting with PpMYB114, potentiated the PpMYB114-mediated accumulation of anthocyanin in pear [156]. In the tea plant, UV-B irradiation-mediated bZIP1 upregulation leads to the promotion of flavonol biosynthesis by binding to the promoters of MYB12, FLS, and UGT and activating their expression; under shading, meanwhile, PIF3 inhibited flavonol accumulation by activating the expression of $M Y B 7$, which encodes a transcriptional repressor [157]. In peach, NAC1 was shown to regulate anthocyanin pigmentation through activating the transcription of MYB10.1, while NAC1 was repressed by SPL1 [158]. In the pear, PyWRKY26 interacts with PybHLH3 and activates the expression of PyMYB114, resulting in anthocyanin biosynthesis [159]. The BTB/TAZ protein MdBT2 represses anthocyanin biosynthesis, and MdGRF11 interacts with, and negatively regulates, MdBT2, leading to an increase in the expression of anthocyanin biosynthesis-related genes via the enhancement of the abundance of MdMYB1 protein [160]. SIBBX20 can bind the SlDFR promoter and directly activate its expression, which augments anthocyanin biosynthesis, while SICSN5, a subunit of the COP9 signalosome, induces the degradation of SIBBX20 by enhancing its ubiquitination [161]. MdARF19 modulates anthocyanin biosynthesis by binding to the promoter of MdLOB52 and further activating its expression [162]. BES1, a positive regulator in brassinosteroid signaling, inhibits the transcription of the MYB proteins MYB11, MYB12, and MYB111, thereby decreasing flavonol biosynthesis [163]

\section{Perspectives}

Flavonoids are abundantly present in land plants where they have diverse functions; as dietary components, they also exert a variety of beneficial effects in humans $[2,16,164,165]$. Elucidating the pathways involved in the biosynthesis of flavonoids will aid in better understanding their functions and potential uses. For example, the heterologous transformation of $\mathrm{F}^{\prime} 5^{\prime} \mathrm{H}$ from Campanula medium (Canterbury bells) and $\mathrm{A3}^{\prime} 5^{\prime} \mathrm{GT}$ (anthocyanin $3^{\prime}, 5^{\prime}-\mathrm{O}^{-}$ glucosyltransferase gene) from Clitoria ternatea (butterfly pea) driven by the native (Chrysanthemum morifolium) F3H promoter induced the synthesis of delphinidin and generated true blue Chrysanthemums [3,6,166]. Flavonoids have also been produced for food and medicine in engineered bacteria. The functional expression of plant-derived $F 3 H$, FLS, and OMT in Corynebacterium glutamicum yielded pterostilbene, kaempferol, and quercetin at high concentrations and purity [167]. In Escherichia coli, cyanidin 3-O-glucoside was generated through the induction of ANS and 3GT using a bicistronic expression cassette [168]. These observations highlight the important application and economic value of deciphering the pathways involved in flavonoid biosynthesis.

Over the past few decades, flavonoid biosynthesis has been among the most intensively investigated secondary metabolic pathways in plant biology, and a considerable number of studies have contributed to revealing the exquisite mechanisms underlying the biosynthesis of flavonoids in plants $[1,135]$. However, several questions remain outstanding. For example, no comprehensive model exists as yet regarding which enzymes catalyze the formation of 3-deoxyanthocyanidin; additionally, the biosynthesis of phlobaphenes needs to be further improved.

Plants are rich in diversity and often produce specific secondary metabolites. Recent studies have identified a unique flavone synthesis pathway in the root of the medicinal plant $S$. baicalensis, which generated root-specific flavones such as baicalein and norwogonin [68,70,71]. Accordingly, whether specific flavonoid biosynthesis pathways and metabolites also exist in other plants warrants further investigation, so as to continuously improve our knowledge of the flavonoid biosynthesis network. 
In addition, combined multi-omics (genomics, transcriptomics, proteomics, and metabolomics) analysis provides a direction for the study of plant synthetic biology. In rice, a flavonoid 7-O-glycosyltransferase (OsUGT706C2) gene with a role in modulating flavonol (kaempferol) and flavone (luteolin and chrysoeriol) metabolism was identified by metabolite-based genome-wide association analysis [169]. Proteomics and transcriptomics, complemented with gas chromatography-mass spectrometry (GC-MS) analysis, aided in elucidating the flavonoid metabolic pathway during seed ripening in Camellia oleifera [170]. The constantly evolving multi-omics technology combined with big data analysis will likely lead to the identification of novel flavonoids and increased knowledge of the flavonoid biosynthesis network.

Author Contributions: W.L. wrote the manuscript; Y.F. and S.Y. created the figures; Z.F. and X.L. edited the manuscript and organized the references; H.Y. and J.L. critically reviewed and corrected the manuscript. All authors have read and agreed to the published version of the manuscript.

Funding: This work was funded by National Key R\&D Program of China (2019YFD1000), Fundamental Research Funds of CAF (CAFYBB2021QD001-1), and Zhejiang Science and Technology Major Program on Agricultural New Variety Breeding (2021C02071-2).

Institutional Review Board Statement: Not applicable.

Informed Consent Statement: Not applicable.

Conflicts of Interest: The authors declare no competing interest.

\section{References}

1. Dong, N.Q.; Lin, H.X. Contribution of phenylpropanoid metabolism to plant development and plant-environment interactions. J. Integr. Plant Biol. 2020, 63, 180-209. [CrossRef] [PubMed]

2. Nabavi, S.M.; Šamec, D.; Tomczyk, M.; Milella, L.; Russo, D.; Habtemariam, S.; Suntar, I.; Rastrelli, L.; Daglia, M.; Xiao, J.; et al. Flavonoid biosynthetic pathways in plants: Versatile targets for metabolic engineering. Biotechnol. Adv. 2018, 38, 107316. [CrossRef]

3. Sasaki, N.; Nakayama, T. Achievements and Perspectives in Biochemistry Concerning Anthocyanin Modification for Blue Flower Coloration. Plant Cell Physiol. 2015, 56, 28-40. [CrossRef]

4. Winkel-Shirley, B. Flavonoid Biosynthesis. A Colorful Model for Genetics, Biochemistry, Cell Biology, and Biotechnology. Plant Physiol. 2001, 126, 485-493. [CrossRef]

5. Tanaka, Y.; Brugliera, F.; Chandler, S. Recent Progress of Flower Colour Modification by Biotechnology. Int. J. Mol. Sci. 2009, 10, 5350-5369. [CrossRef]

6. Noda, N.; Yoshioka, S.; Kishimoto, S.; Nakayama, M.; Douzono, M.; Tanaka, Y.; Aida, R. Generation of blue chrysanthemums by anthocyanin B-ring hydroxylation and glucosylation and its coloration mechanism. Sci. Adv. 2017, 3, e1602785. [CrossRef] [PubMed]

7. Sun, C.; Zhang, M.; Dong, H.; Liu, W.; Guo, L.; Wang, X. A spatially-resolved approach to visualize the distribution and biosynthesis of flavones in Scutellaria baicalensis Georgi. J. Pharm. Biomed. Anal. 2020, 179, 113014. [CrossRef]

8. Grotewold, E. The genetics and biochemistry of floral pigments. Annu. Rev. Plant Biol. 2006, 57, 761-780. [CrossRef]

9. Cavaiuolo, M.; Cocetta, G.; Ferrante, A. The Antioxidants Changes in Ornamental Flowers during Development and Senescence. Antioxidants 2013, 2, 132-155. [CrossRef] [PubMed]

10. Iwashina, T. Flavonoid Function and Activity to Plants and Other Organisms. Biol. Sci. Space 2003, 17, 24-44. [CrossRef] [PubMed]

11. Zhang, P.; Du, H.; Wang, J.; Pu, Y.; Yang, C.; Yan, R.; Yang, H.; Cheng, H.; Yu, D. Multiplex CRISPR/Cas9-mediated metabolic engineering increases soya bean isoflavone content and resistance to soya bean mosaic virus. Plant Biotechnol. J. 2020, 18, 1384-1395. [CrossRef]

12. Pourcel, L.; Routaboul, J.M.; Cheynier, V.; Lepiniec, L.; Debeaujon, I. Flavonoid oxidation in plants: From biochemical properties to physiological functions. Trends Plant Sci. 2007, 12, 29-36. [CrossRef] [PubMed]

13. Tan, H.; Man, C.; Xie, Y.; Yan, J.; Chu, J.; Huang, J. A Crucial Role of GA-Regulated Flavonol Biosynthesis in Root Growth of Arabidopsis. Mol. Plant 2019, 12, 521-537. [CrossRef]

14. Selvakumar, P.; Badgeley, A.; Murphy, P.; Anwar, H.; Sharma, U.; Lawrence, K.; Lakshmikuttyamma, A. Flavonoids and Other Polyphenols Act as Epigenetic Modifiers in Breast Cancer. Nutrients 2020, 12, 761. [CrossRef]

15. Imran, M.; Rauf, A.; Abu-Izneid, T.; Nadeem, M.; Shariati, M.A.; Khan, I.A.; Imran, A.; Orhan, I.E.; Rizwan, M.; Atif, M.; et al. Luteolin, a flavonoid, as an anticancer agent: A review. Biomed. Pharmacother. 2019, 112, 108612. [CrossRef]

16. Fernandes, I.; Pérez-Gregorio, R.; Soares, S.; Mateus, N.; de Freitas, V. Wine Flavonoids in Health and Disease Prevention. Molecules 2017, 22, 292. [CrossRef] 
17. Wang, Z.L.; Wang, S.; Kuang, Y.; Hu, Z.M.; Qiao, X.; Ye, M. A comprehensive review on phytochemistry, pharmacology, and flavonoid biosynthesis of Scutellaria baicalensis. Pharm. Biol. 2018, 56, 465-484. [CrossRef] [PubMed]

18. Williams, J.S.; Thomas, M.; Clarke, D.J. The gene stlA encodes a phenylalanine ammonia-lyase that is involved in the production of a stilbene antibiotic in Photorhabdus luminescens TT01. Microbiology 2005, 151, 2543-2550. [CrossRef] [PubMed]

19. Barros, J.; Dixon, R.A. Plant Phenylalanine/Tyrosine Ammonia-lyases. Trends Plant Sci. 2020, 25, 66-79. [CrossRef]

20. Cheng, G.W.; Breen, P.J. Activity of Phenylalanine Ammonia-Lyase (PAL) and Concentrations of Anthocyanins and Phenolics in Developing Strawberry Fruit. J. Am. Soc. Hortic. Sci. 1991, 116, 865-869. [CrossRef]

21. Wohl, J.; Petersen, M. Functional expression and characterization of cinnamic acid 4-hydroxylase from the hornwort Anthoceros agrestis in Physcomitrella patens. Plant Cell Rep. 2020, 39, 597-607. [CrossRef]

22. Li, Y.; Kim, J.I.; Pysh, L.; Chapple, C. Four Isoforms of Arabidopsis 4-Coumarate: CoA Ligase Have Overlapping yet Distinct Roles in Phenylpropanoid Metabolism. Plant Physiol. 2015, 169, 2409-2421. [CrossRef]

23. Pietrowska-Borek, M.; Chadzinikolau, T.; Kozłowska, M. Effect of urban pollution on 4-coumarate: CoA ligase and flavonoid accumulation in Berberis thunbergii. Dendrobiology 2010, 64, 79-85.

24. Mizutani, M.; Ohta, D.; Sato, R. Isolation of a cDNA and a Genomic Clone Encoding Cinnamate 4-Hydroxylase from Arabidopsis and Its Expression Manner in Planta. Plant Physiol. 1997, 113, 755-763. [CrossRef] [PubMed]

25. Wang, J.; Li, G.; Li, C.; Zhang, C.; Cui, L.; Ai, G.; Wang, X.; Zheng, F.; Zhang, D.; Larkin, R.M.; et al. NF-Y plays essential roles in flavonoid biosynthesis by modulating histone modifications in tomato. New Phytol. 2020, 229, 3237-3252. [CrossRef]

26. Deng, X.; Bashandy, H.; Ainasoja, M.; Kontturi, J.; Pietiainen, M.; Laitinen, R.A.; Albert, V.A.; Valkonen, J.P.; Elomaa, P.; Teeri, T.H. Functional diversification of duplicated chalcone synthase genes in anthocyanin biosynthesis of Gerbera hybrida. New Phytol. 2013, 201, 1469-1483. [CrossRef] [PubMed]

27. Zhang, X.; Abrahan, C.; Colquhoun, T.A.; Liu, C.J. A Proteolytic Regulator Controlling Chalcone Synthase Stability and Flavonoid Biosynthesis in Arabidopsis. Plant Cell 2017, 29, 1157-1174. [CrossRef] [PubMed]

28. Schijlen, E.G.; de Vos, C.H.; Martens, S.; Jonker, H.H.; Rosin, F.M.; Molthoff, J.W.; Tikunov, Y.M.; Angenent, G.C.; van Tunen, A.J.; Bovy, A.G. RNA interference silencing of chalcone synthase, the first step in the flavonoid biosynthesis pathway, leads to parthenocarpic tomato fruits. Plant Physiol. 2007, 144, 1520-1530. [CrossRef] [PubMed]

29. Bomati, E.K.; Austin, M.B.; Bowman, M.E.; Dixon, R.A.; Noel, J.P. Structural Elucidation of Chalcone Reductase and Implications for Deoxychalcone Biosynthesis. J. Biol. Chem. 2005, 280, 30496-30503. [CrossRef] [PubMed]

30. Shimada, N.; Nakatsuka, T.; Nishihara, M.; Yamamura, S.; Ayabe, S.; Aoki, T. Isolation and characterization of a cDNA encoding polyketide reductase in Lotus japonicus. Plant Biotechnol. 2006, 23, 509-513. [CrossRef]

31. Zhou, L.; Wang, Y.; Peng, Z. Advances in Study on Formation Mechanism and Genetic Engineering of Yellow Flowers. Sci. Silvae Sin. 2009, 45, 111-119.

32. Togami, J.; Okuhara, H.; Nakamura, N.; Ishiguro, K.; Hirose, C.; Ochiai, M.; Fukui, Y.; Yamaguchi, M.; Tanaka, Y. Isolation of cDNAs encoding tetrahydroxychalcone $2^{\prime}$-glucosyltransferase activity from carnation, cyclamen, and catharanthus. Plant Biotechnol. 2011, 28, 231-238. [CrossRef]

33. Yoshida, H.; Itoh, Y.; Ozeki, Y.; Iwashina, T.; Yamaguchi, M. Variation in chalcononaringenin 2'-O-glucoside content in the petals of carnations (Dianthus caryophyllus) bearing yellow flowers. Sci. Hortic. 2004, 99, 175-186. [CrossRef]

34. Parage, C.; Tavares, R.; Réty, S.; Baltenweck-Guyot, R.; Poutaraud, A.; Renault, L.; Heintz, D.; Lugan, R.; Marais, G.A.; Aubourg, S.; et al. Structural, functional, and evolutionary analysis of the unusually large stilbene synthase gene family in grapevine. Plant Physiol. 2012, 160, 1407-1419. [CrossRef] [PubMed]

35. Wang, X.; Hu, H.; Wu, Z.; Fan, H.; Wang, G.; Chai, T.; Wang, H. Tissue-specific transcriptome analyses reveal candidate genes for stilbene, flavonoid and anthraquinone biosynthesis in the medicinal plant Polygonum cuspidatum. BMC Genom. 2021, $22,353$. [CrossRef] [PubMed]

36. Chong, J.; Poutaraud, A.; Hugueney, P. Metabolism and roles of stilbenes in plants. Plant Sci. 2009, 177, 143-155. [CrossRef]

37. Peng, W.; Qin, R.; Li, X.; Zhou, H. Botany, phytochemistry, pharmacology, and potential application of Polygonum cuspidatum Sieb.et Zucc.: A review. J. Ethnopharmacol. 2013, 148, 729-745. [CrossRef]

38. Sparvoli, F.; Martin, C.; Scienza, A.; Gavazzi, G.; Tonelli, C. Cloning and molecular analysis of structural genes involved in flavonoid and stilbene biosynthesis in grape (Vitis vinifera L.). Plant Mol. Biol. 1994, 24, 743-755. [CrossRef] [PubMed]

39. Suprun, A.R.; Ogneva, Z.V.; Dubrovina, A.S.; Kiselev, K.V. Effect of spruce PjSTS1a, PjSTS2, or PjSTS3 gene overexpression on stilbene biosynthesis in callus cultures of Vitis amurensis Rupr. Biotechnol. Appl. Biochem. 2020, 67, 234-239. [CrossRef]

40. Yang, T.; Fang, L.; Sanders, S.; Jayanthi, S.; Rajan, G.; Podicheti, R.; Thallapuranam, S.K.; Mockaitis, K.; Medina-Bolivar, F. Stilbenoid prenyltransferases define key steps in the diversification of peanut phytoalexins. J. Biol. Chem. 2018, 293, 28-46. [CrossRef]

41. Valletta, A.; Iozia, L.M.; Leonelli, F. Impact of Environmental Factors on Stilbene Biosynthesis. Plants 2021, 10, 90. [CrossRef]

42. Alsayari, A.; Muhsinah, A.B.; Hassan, M.Z.; Ahsan, M.J.; Alshehri, J.A.; Begum, N. Aurone: A biologically attractive scaffold as anticancer agent. Eur. J. Med. Chem. 2019, 166, 417-431. [CrossRef] [PubMed]

43. Nakayama, T.; Yonekura-Sakakibara, K.; Sato, T.; Kikuchi, S.; Fukui, Y.; Fukuchi-Mizutani, M.; Ueda, T.; Nakao, M.; Tanaka, Y.; Kusumi, T.; et al. Aureusidin Synthase: A Polyphenol Oxidase Homolog Responsible for Flower Coloration. Science 2000, 290, 1163-1166. [CrossRef] [PubMed]

44. Nakayama, T. Enzymology of Aurone Biosynthesis. J. Biosci. Bioeng. 2002, 94, 487-491. [CrossRef] 
45. Ono, E.; Nakayama, T. Molecular Breeding of Novel Yellow Flowers by Engineering the Aurone Biosynthetic Pathway. Transgenic Plant J. 2007, 1, 66-80.

46. Ono, E.; Hatayama, M.; Isono, Y.; Sato, T.; Watanabe, R.; Yonekura-Sakakibara, K.; Fukuchi-Mizutani, M.; Tanaka, Y.; Kusumi, T.; Nishino, T.; et al. Localization of a flavonoid biosynthetic polyphenol oxidase in vacuoles. Plant J. 2006, 45, 133-143. [CrossRef]

47. Ono, E.; Fukuchi-Mizutani, M.; Nakamura, N.; Fukui, Y.; Yonekura-Sakakibara, K.; Yamaguchi, M.; Nakayama, T.; Tanaka, T.; Kusumi, T.; Tanaka, Y. Yellow flowers generated by expression of the aurone biosynthetic pathway. Proc. Natl. Acad. Sci. USA 2006, 103, 11075-11080. [CrossRef]

48. Boucherle, B.; Peuchmaur, M.; Boumendjel, A.; Haudecoeur, R. Occurrences, biosynthesis and properties of aurones as high-end evolutionary products. Phytochemistry 2017, 142, 92-111. [CrossRef]

49. Nakayama, T.; Sato, T.; Fukui, Y.; Yonekura-Sakakibara, K.; Hayashi, H.; Tanaka, Y.; Kusumi, T.; Nishino, T. Specificity analysis and mechanism of aurone synthesis catalyzed by aureusidin synthase, a polyphenol oxidase homolog responsible for flower coloration. FEBS Lett. 2001, 499, 107-111. [CrossRef]

50. Hoshino, A.; Mizuno, T.; Shimizu, K.; Mori, S.; Fukada-Tanaka, S.; Furukawa, K.; Ishiguro, K.; Tanaka, Y.; Iida, S. Generation of Yellow Flowers of the Japanese Morning Glory by Engineering Its Flavonoid Biosynthetic Pathway toward Aurones. Plant Cell Physiol. 2019, 60, 1871-1879. [CrossRef] [PubMed]

51. Lin, S.; Singh, R.K.; Moehninsi; Navarre, D.A. R2R3-MYB transcription factors, StmiR858 and sucrose mediate potato flavonol biosynthesis. Hortic. Res. 2021, 8, 25. [CrossRef]

52. Yin, Y.C.; Zhang, X.D.; Gao, Z.Q.; Hu, T.; Liu, Y. The Research Progress of Chalcone Isomerase (CHI) in Plants. Mol. Biotechnol. 2019, 61, 32-52. [CrossRef]

53. Zhu, J.; Zhao, W.; Li, R.; Guo, D.; Li, H.; Wang, Y.; Mei, W.; Peng, S. Identification and Characterization of Chalcone Isomerase Genes Involved in Flavonoid Production in Dracaena cambodiana. Front. Plant Sci. 2021, 12, 616396. [CrossRef]

54. Chao, N.; Wang, R.F.; Hou, C.; Yu, T.; Miao, K.; Cao, F.Y.; Fang, R.J.; Liu, L. Functional characterization of two chalcone isomerase (CHI) revealing their responsibility for anthocyanins accumulation in mulberry. Plant Physiol. Biochem. 2021, 161, 65-73. [CrossRef]

55. Jiang, W.; Yin, Q.; Wu, R.; Zheng, G.; Liu, J.; Dixon, R.A.; Pang, Y. Role of a chalcone isomerase-like protein in flavonoid biosynthesis in Arabidopsis thaliana. J. Exp. Bot. 2015, 66, 7165-7179. [CrossRef] [PubMed]

56. Nishihara, M.; Nakatsuka, T.; Yamamura, S. Flavonoid components and flower color change in transgenic tobacco plants by suppression of chalcone isomerase gene. FEBS Lett. 2005, 579, 6074-6078. [CrossRef] [PubMed]

57. Casas, M.I.; Falcone-Ferreyra, M.L.; Jiang, N.; Mejía-Guerra, M.K.; Rodríguez, E.; Wilson, T.; Engelmeier, J.; Casati, P.; Grotewold, E. Identification and Characterization of Maize salmon silks Genes Involved in Insecticidal Maysin Biosynthesis. Plant Cell 2016, 28, 1297-1309. [CrossRef] [PubMed]

58. Dinkins, R.D.; Hancock, J.; Coe, B.L.; May, J.B.; Goodman, J.P.; Bass, W.T.; Liu, J.; Fan, Y.; Zheng, Q.; Zhu, H. Isoflavone levels, nodulation and gene expression profiles of a CRISPR/Cas9 deletion mutant in the isoflavone synthase gene of red clover. Plant Cell Rep. 2021, 40, 517-528. [CrossRef]

59. Zuk, M.; Szperlik, J.; Hnitecka, A.; Szopa, J. Temporal biosynthesis of flavone constituents in flax growth stages. Plant Physiol. Biochem. 2019, 142, 234-245. [CrossRef]

60. Wu, Q.; Zhang, H.; Wang, X.; Zhao, W.; Zhou, X.; Wang, L. Research progress on flower color of waterlily (Nymphaea). Acta Hortic. Sin. 2021, 48, 1-13.

61. Wu, J.; Wang, X.C.; Liu, Y.; Du, H.; Shu, Q.Y.; Su, S.; Wang, L.J.; Li, S.S.; Wang, L.S. Flavone synthases from Lonicera japonica and L. macranthoides reveal differential flavone accumulation. Sci. Rep. 2016, 6, 19245. [CrossRef]

62. Li, H.; Li, D.; Yang, Z.; Zeng, Q.; Luo, Y.; He, N. Flavones Produced by Mulberry Flavone Synthase Type I Constitute a Defense Line against the Ultraviolet-B Stress. Plants 2020, 9, 215. [CrossRef] [PubMed]

63. Yun, C.S.; Yamamoto, T.; Nozawa, A.; Tozawa, Y. Expression of parsley flavone synthase I establishes the flavone biosynthetic pathway in Arabidopsis thaliana. Biosci. Biotechnol. Biochem. 2008, 72, 968-973. [CrossRef] [PubMed]

64. Wei, S.; Zhang, W.; Fu, R.; Zhang, Y. Genome-wide characterization of 2-oxoglutarate and Fe(II)-dependent dioxygenase family genes in tomato during growth cycle and their roles in metabolism. BMC Genom. 2021, 22, 126. [CrossRef] [PubMed]

65. Wang, H.; Liu, S.; Wang, T.; Liu, H.; Xu, X.; Chen, K.; Zhang, P. The moss flavone synthase I positively regulates the tolerance of plants to drought stress and UV-B radiation. Plant Sci. 2020, 298, 110591. [CrossRef]

66. Zhang, J.; Subramanian, S.; Zhang, Y.; Yu, O. Flavone synthases from Medicago truncatula are flavanone-2-hydroxylases and are important for nodulation. Plant Physiol. 2007, 144, 741-751. [CrossRef]

67. Lam, P.Y.; Lui, A.C.W.; Yamamura, M.; Wang, L.; Takeda, Y.; Suzuki, S.; Liu, H.; Zhu, F.Y.; Chen, M.X.; Zhang, J.; et al. Recruitment of specific flavonoid B-ring hydroxylases for two independent biosynthesis pathways of flavone-derived metabolites in grasses. New Phytol. 2019, 223, 204-219. [CrossRef]

68. Zhao, Q.; Zhang, Y.; Wang, G.; Hill, L.; Weng, J.K.; Chen, X.Y.; Xue, H.; Martin, C. A specialized flavone biosynthetic pathway has evolved in the medicinal plant, Scutellaria baicalensis. Sci. Adv. 2016, 2, e1501780. [CrossRef]

69. Fang, Y.M.; Cui, M.Y.; Liu, J.; Pei, T.L.; Wei, Y.K.; Zhao, Q. Study advance in biosynthesis of flavone from Scutellaria. China J. Chin. Mater. Med. 2020, 45, 4819-4826.

70. Zhao, Q.; Yang, J.; Cui, M.Y.; Liu, J.; Fang, Y.; Yan, M.; Qiu, W.; Shang, H.; Xu, Z.; Yidiresi, R.; et al. The Reference Genome Sequence of Scutellaria baicalensis Provides Insights into the Evolution of Wogonin Biosynthesis. Mol. Plant 2019, 12, 935-950. [CrossRef] 
71. Zhao, Q.; Cui, M.Y.; Levsh, O.; Yang, D.; Liu, J.; Li, J.; Hill, L.; Yang, L.; Hu, Y.; Weng, J.K.; et al. Two CYP82D Enzymes Function as Flavone Hydroxylases in the Biosynthesis of Root-Specific 4'-Deoxyflavones in Scutellaria baicalensis. Mol. Plant 2018, 11, 135-148. [CrossRef] [PubMed]

72. Liu, X.; Cheng, J.; Zhu, X.; Zhang, G.; Yang, S.; Guo, X.; Jiang, H.; Ma, Y. De Novo Biosynthesis of Multiple Pinocembrin Derivatives in Saccharomyces cerevisiae. ACS Synth. Biol. 2020, 9, 3042-3051. [CrossRef] [PubMed]

73. Chu, S.; Wang, J.; Zhu, Y.; Liu, S.; Zhou, X.; Zhang, H.; Wang, C.E.; Yang, W.; Tian, Z.; Cheng, H.; et al. An R2R3-type MYB transcription factor, GmMYB29, regulates isoflavone biosynthesis in soybean. PLoS Genet. 2017, 13, e1006770. [CrossRef] [PubMed]

74. Bosse, M.A.; Silva, M.B.D.; Oliveira, N.; Araujo, M.A.; Rodrigues, C.; Azevedo, J.P.; Reis, A.R.D. Physiological impact of flavonoids on nodulation and ureide metabolism in legume plants. Plant Physiol. Biochem. 2021, 166, 512-521. [CrossRef]

75. Pandey, A.; Misra, P.; Khan, M.P.; Swarnkar, G.; Tewari, M.C.; Bhambhani, S.; Trivedi, R.; Chattopadhyay, N.; Trivedi, P.K. Co-expression of Arabidopsis transcription factor, AtMYB12, and soybean isoflavone synthase, GmIFS1, genes in tobacco leads to enhanced biosynthesis of isoflavones and flavonols resulting in osteoprotective activity. Plant Biotechnol. J. 2014, 12, 69-80. [CrossRef]

76. Sohn, S.I.; Pandian, S.; Oh, Y.J.; Kang, H.J.; Cho, W.S.; Cho, Y.S. Metabolic Engineering of Isoflavones: An Updated Overview. Front. Plant Sci. 2021, 12, 670103. [CrossRef]

77. Veremeichik, G.N.; Grigorchuk, V.P.; Butovets, E.S.; Lukyanchuk, L.M.; Brodovskaya, E.V.; Bulgakov, D.V.; Bulgakov, V.P. Isoflavonoid biosynthesis in cultivated and wild soybeans grown in the field under adverse climate conditions. Food Chem. 2021, 342, 128292. [CrossRef]

78. Artigot, M.-P.; Daydé, J.; Berger, M. Expression of Key Genes of the Isoflavonoid Pathway in Hypocotyls and Cotyledons During Soybean Seed Maturation. Crop. Sci. 2013, 53, 1096-1108. [CrossRef]

79. He, X.; Blount, J.W.; Ge, S.; Tang, Y.; Dixon, R.A. A genomic approach to isoflavone biosynthesis in kudzu (Pueraria lobata). Planta 2011, 233, 843-855. [CrossRef]

80. Vadivel, A.K.A.; McDowell, T.; Renaud, J.B.; Dhaubhadel, S. A combinatorial action of GmMYB176 and GmbZIP5 controls isoflavonoid biosynthesis in soybean (Glycine max). Commun. Biol. 2021, 4, 356. [CrossRef]

81. Ma, J.; Li, C.; Wei, Y.; Li, L.; Zhao, Y. The pathway of isoflavone biosynthesis and its regulation. J. Northeast. Agric. Univ. 2007, 38, 392-396.

82. Malla, A.; Shanmugaraj, B.; Srinivasan, B.; Sharma, A.; Ramalingam, S. Metabolic Engineering of Isoflavonoid Biosynthesis by Expressing Glycine max Isoflavone Synthase in Allium cepa L. for Genistein Production. Plants 2021, 10, 52. [CrossRef] [PubMed]

83. Cox, L.D.; Munholland, S.; Mats, L.; Zhu, H.; Crosby, W.L.; Lukens, L.; Pauls, K.P.; Bozzo, G.G. The Induction of the Isoflavone Biosynthesis Pathway Is Associated with Resistance to Common Bacterial Blight in Phaseolus vulgaris L. Metabolites 2021, 11, 433. [CrossRef]

84. Uchida, K.; Akashi, T.; Aoki, T. The Missing Link in Leguminous Pterocarpan Biosynthesis is a Dirigent Domain-Containing Protein with Isoflavanol Dehydratase Activity. Plant Cell Physiol. 2017, 58, 398-408. [CrossRef] [PubMed]

85. Yao, S.; Lan, Z.; Huang, R.; Tan, Y.; Huang, D.; Gu, J.; Pan, C. Hormonal and transcriptional analyses provides new insights into the molecular mechanisms underlying root thickening and isoflavonoid biosynthesis in Callerya speciosa (Champ. ex Benth.) Schot. Sci. Rep. 2021, 11, 9. [CrossRef]

86. Landoni, M.; Puglisi, D.; Cassani, E.; Borlini, G.; Brunoldi, G.; Comaschi, C.; Pilu, R. Phlobaphenes modify pericarp thickness in maize and accumulation of the fumonisin mycotoxins. Sci. Rep. 2020, 10, 1417. [CrossRef]

87. Cassani, E.; Puglisi, D.; Cantaluppi, E.; Landoni, M.; Giupponi, L.; Giorgi, A.; Pilu, R. Genetic studies regarding the control of seed pigmentation of an ancient European pointed maize (Zea mays L.) rich in phlobaphenes: The "Nero Spinoso" from the Camonica valley. Genet. Resour. Crop. Evol. 2016, 64, 761-773. [CrossRef]

88. Tuerck, J.A.; Fromm, M.E. Elements of the maize $A 1$ promoter required for transactivation by the anthocyanin $B / C 1$ or phlobaphene $P$ regulatory genes. Plant Cell 1994, 6, 1655-1663.

89. Sharma, M.; Chai, C.; Morohashi, K.; Grotewold, E.; Snook, M.E.; Chopra, S. Expression of flavonoid 3'-hydroxylase is controlled by P1, the regulator of 3-deoxyflavonoid biosynthesis in maize. BMC Plant Biol. 2012, 12, 196. [CrossRef]

90. Sekhon, R.S.; Kuldau, G.; Mansfield, M.; Chopra, S. Characterization of Fusarium-induced expression of flavonoids and PR genes in maize. Physiol. Mol. Plant Pathol. 2006, 69, 109-117. [CrossRef]

91. Halbwirth, H.; Martens, S.; Wienand, U.; Forkmann, G.; Stich, K. Biochemical formation of anthocyanins in silk tissue of Zea mays. Plant Sci. 2003, 164, 489-495. [CrossRef]

92. Bruce, W.; Folkerts, O.; Garnaat, C.; Crasta, O.; Roth, B.; Bowen, B. Expression Profiling of the Maize Flavonoid Pathway Genes Controlled by Estradiol-Inducible Transcription Factors CRC and P. Plant Cell 2000, 12, 65-79. [CrossRef]

93. Wu, B.; Chang, H.; Marini, R.; Chopra, S.; Reddivari, L. Characterization of Maize Near-Isogenic Lines With Enhanced Flavonoid Expression to Be Used as Tools in Diet-Health Complexity. Front. Plant Sci. 2021, 11, 619598. [CrossRef]

94. Winefield, C.S.; Lewis, D.H.; Swinny, E.E.; Zhang, H.B.; Arathoon, H.S.; Fischer, T.C.; Halbwirth, H.; Stich, K.; Gosch, C.; Forkmann, G.; et al. Investigation of the biosynthesis of 3-deoxyanthocyanins in Sinningia cardinalis. Physiol. Plant. 2005, 124, 419-430. [CrossRef]

95. Song, X.; Diao, J.; Ji, J.; Wang, G.; Guan, C.; Jin, C.; Wang, Y. Molecular cloning and identification of a flavanone 3-hydroxylase gene from Lycium chinense, and its overexpression enhances drought stress in tobacco. Plant Physiol. Biochem. 2016, 98, 89-100. [CrossRef] [PubMed] 
96. Tu, Y.; Liu, F.; Guo, D.; Fan, L.; Zhu, Z.; Xue, Y.; Gao, Y.; Guo, M. Molecular characterization of flavanone 3-hydroxylase gene and flavonoid accumulation in two chemotyped safflower lines in response to methyl jasmonate stimulation. BMC Plant Biol. 2016, 16, 132. [CrossRef]

97. Wang, L.; Lui, A.C.W.; Lam, P.Y.; Liu, G.; Godwin, I.D.; Lo, C. Transgenic expression of flavanone 3-hydroxylase redirects flavonoid biosynthesis and alleviates anthracnose susceptibility in sorghum. Plant Biotechnol. J. 2020, 18, 2170-2172. [CrossRef] [PubMed]

98. Cao, Y.; Xing, M.; Xu, C.; Li, X. Biosynthesis of Flavonol and Its Regulation in Plants. Acta Hortic. Sin. 2018, 45, 177-192.

99. Busche, M.; Acatay, C.; Martens, S.; Weisshaar, B.; Stracke, R. Functional Characterisation of Banana (Musa spp.) 2-OxoglutarateDependent Dioxygenases Involved in Flavonoid Biosynthesis. Front. Plant Sci. 2021, 12, 701780. [CrossRef] [PubMed]

100. Mou, J.; Zhang, Z.; Qiu, H.; Lu, Y.; Zhu, X.; Fan, Z.; Zhang, Q.; Ye, J.; Fernie, A.R.; Cheng, Y.; et al. Multiomics-based dissection of citrus flavonoid metabolism using a Citrus reticulata $x$ Poncirus trifoliata population. Hortic. Res. 2021, 8, 56. [CrossRef] [PubMed]

101. Gao, S.; Zhou, J.; Chen, J. Identification of flavonoids 3-hydroxylase from [Silybum marianum (L.) Gaertn] and its application in enhanced production of taxifolin. Chin. J. Biotechnol. 2020, 36, 2838-2849.

102. Xu, M.; Yi, H.; Guo, J.; Tang, J.; Lin, S.; Yang, Z.; Zheng, J. Cloning and Expression Analysis of a Flavanone 3-hydroxylase Gene from Ampelopsis grossedentata. Acta Bot. Boreali-Occident. Sin. 2020, 40, 185-192.

103. Wen, C.H.; Tsao, N.W.; Wang, S.Y.; Chu, F.H. Color variation in young and senescent leaves of Formosan sweet gum (Liquidambar formosana) by the gene regulation of anthocyanidin biosynthesis. Physiol. Plant. 2021, 172, 1750-1763. [CrossRef]

104. Zhang, Q.; Wang, Y.; Ou, Y.; Ke, Y.; Yao, Y.; Wang, M.; Ai, Y. Research Advances of Genes Responsible for Flower Colors in Orchidaceae. Acta Hortic. Sin. 2021, 49, 2057-2072.

105. Han, Y.; Vimolmangkang, S.; Soria-Guerra, R.E.; Rosales-Mendoza, S.; Zheng, D.; Lygin, A.V.; Korban, S.S. Ectopic expression of apple $F 3^{\prime} H$ genes contributes to anthocyanin accumulation in the Arabidopsis $t t 7$ mutant grown under nitrogen stress. Plant Physiol. 2010, 153, 806-820. [CrossRef] [PubMed]

106. Takahashi, R.; Dubouzet, J.G.; Matsumura, H.; Yasuda, K.; Iwashina, T. A new allele of flower color gene W1 encoding flavonoid 3'5'-hydroxylase is responsible for light purple flowers in wild soybean Glycine soja. BMC Plant Biol. 2010, 10, 155. [CrossRef] [PubMed]

107. Meng, X.; Li, Y.; Zhou, T.; Sun, W.; Shan, X.; Gao, X.; Wang, L. Functional Differentiation of Duplicated Flavonoid 3O-Glycosyltransferases in the Flavonol and Anthocyanin Biosynthesis of Freesia hybrida. Front. Plant Sci. 2019, 10, 1330. [CrossRef] [PubMed]

108. Yu, Z.; Dong, W.; Teixeira da Silva, J.A.; He, C.; Si, C.; Duan, J. Ectopic expression of DoFLS1 from Dendrobium officinale enhances flavonol accumulation and abiotic stress tolerance in Arabidopsis thaliana. Protoplasma 2021, 258, 803-815. [CrossRef] [PubMed]

109. Chapman, J.M.; Muday, G.K. Flavonols modulate lateral root emergence by scavenging reactive oxygen species in Arabidopsis thaliana. J. Biol. Chem. 2021, 296, 100222. [CrossRef]

110. Fang, F.; Wang, F.Z. Research Progress on Key Genes of Flavonol Biosynthesis in Plants. Sci. Technol. Food Ind. 2018, 39, 335-340.

111. Irmisch, S.; Ruebsam, H.; Jancsik, S.; Man Saint Yuen, M.; Madilao, L.L.; Bohlmann, J. Flavonol Biosynthesis Genes and Their Use in Engineering the Plant Antidiabetic Metabolite Montbretin A. Plant Physiol. 2019, 180, 1277-1290. [CrossRef] [PubMed]

112. Jiang, X.; Shi, Y.; Fu, Z.; Li, W.W.; Lai, S.; Wu, Y.; Wang, Y.; Liu, Y.; Gao, L.; Xia, T. Functional characterization of three flavonol synthase genes from Camellia sinensis: Roles in flavonol accumulation. Plant Sci. 2020, 300, 110632. [CrossRef]

113. Park, S.; Kim, D.H.; Yang, J.H.; Lee, J.Y.; Lim, S.H. Increased Flavonol Levels in Tobacco Expressing AcFLS Affect Flower Color and Root Growth. Int. J. Mol. Sci. 2020, 21, 1011. [CrossRef] [PubMed]

114. Meyer, P.; Heidmann, I.; Forkmann, G.; Saedler, H. A new petunia flower colour generated by transformation of a mutant with a maize gene. Nature 1987, 330, 677-678. [CrossRef] [PubMed]

115. Shimada, N.; Sasaki, R.; Sato, S.; Kaneko, T.; Tabata, S.; Aoki, T.; Ayabe, S. A comprehensive analysis of six dihydroflavonol 4-reductases encoded by a gene cluster of the Lotus japonicus genome. J. Exp. Bot. 2005, 56, 2573-2585. [CrossRef]

116. LaFountain, A.M.; Yuan, Y.W. Repressors of anthocyanin biosynthesis. New Phytol. 2021, 231, 933-949. [CrossRef] [PubMed]

117. Yan, H.; Pei, X.; Zhang, H.; Li, X.; Zhang, X.; Zhao, M.; Chiang, V.L.; Sederoff, R.R.; Zhao, X. MYB-Mediated Regulation of Anthocyanin Biosynthesis. Int. J. Mol. Sci. 2021, 22, 3103. [CrossRef] [PubMed]

118. Wang, F.; Wang, X.J.; Zhao, S.N.; Yan, J.R.; Bu, X.; Zhang, Y.; Liu, Y.F.; Xu, T.; Qi, M.F.; Qi, H.Y.; et al. Light Regulation of Anthocyanin Biosynthesis in Horticultural Crops. Sci. Agric. Sin. 2020, 53, 4904-4917.

119. Xie, S.; Zhao, T.; Zhang, Z.; Meng, J. Reduction of Dihydrokaempferol by Vitis vinfera Dihydroflavonol 4-Reductase to Produce Orange Pelargonidin-Type Anthocyanins. J. Agric. Food Chem. 2018, 66, 3524-3532. [CrossRef]

120. Feng, X.; Zhang, Y.; Wang, H.; Tian, Z.; Xin, S.; Zhu, P. The dihydroflavonol 4-reductase BoDFR1 drives anthocyanin accumulation in pink-leaved ornamental kale. Theor. Appl. Genet. 2020, 134, 159-169. [CrossRef] [PubMed]

121. Chen, W.; Xiao, Z.; Wang, Y.; Wang, J.; Zhai, R.; Lin-Wang, K.; Espley, R.; Ma, F.; Li, P. Competition between anthocyanin and kaempferol glycosides biosynthesis affects pollen tube growth and seed set of Malus. Hortic. Res. 2021, 8, 173. [CrossRef]

122. Solfanelli, C.; Poggi, A.; Loreti, E.; Alpi, A.; Perata, P. Sucrose-specific induction of the anthocyanin biosynthetic pathway in Arabidopsis. Plant Physiol. 2006, 140, 637-646. [CrossRef] [PubMed]

123. Naing, A.H.; Kim, C.K. Roles of R2R3-MYB transcription factors in transcriptional regulation of anthocyanin biosynthesis in horticultural plants. Plant Mol. Biol. 2018, 98, 1-18. [CrossRef] 
124. Xu, F.; Cheng, H.; Cai, R.; Li, L.L.; Chang, J.; Zhu, J.; Zhang, F.X.; Chen, L.J.; Wang, Y.; Cheng, S.H.; et al. Molecular cloning and function analysis of an anthocyanidin synthase gene from Ginkgo biloba, and its expression in abiotic stress responses. Mol. Cells 2008, 26, 536-547. [PubMed]

125. Giampieri, F.; Gasparrini, M.; Forbes-Hernandez, T.Y.; Mazzoni, L.; Capocasa, F.; Sabbadini, S.; Alvarez-Suarez, J.M.; Afrin, S.; Rosati, C.; Pandolfini, T.; et al. Overexpression of the Anthocyanidin Synthase (ANS) Gene in Strawberry Enhances Antioxidant Capacity and Cytotoxic Effects on Human Hepatic Cancer Cells. J. Agric. Food Chem. 2018, 66, 581-592. [CrossRef] [PubMed]

126. Brugliera, F.; Tao, G.Q.; Tems, U.; Kalc, G.; Mouradova, E.; Price, K.; Stevenson, K.; Nakamura, N.; Stacey, I.; Katsumoto, Y.; et al. Violet/blue chrysanthemums-Metabolic engineering of the anthocyanin biosynthetic pathway results in novel petal colors. Plant Cell Physiol. 2013, 54, 1696-1710. [CrossRef] [PubMed]

127. Zhang, T.; Zhang, H.; Wu, R. Recent Advances on Blue Flower Formation. Chin. Bull. Bot. 2020, 55, $216-227$.

128. Veitch, N.C.; Grayer, R.J. Flavonoids and their glycosides, including anthocyanins. Nat. Prod. Rep. 2008, 25, 555-611. [CrossRef] [PubMed]

129. Yagishita, Y.; Mihara, M.; Kohno, Y.; Shibata, M. Photochromic Properties of 3-Deoxyanthocyanidin Pigments in Nontoxic Solvents. J. Food Sci. 2016, 81, E2950-E2955. [CrossRef]

130. Ibraheem, F.; Gaffoor, I.; Tan, Q.; Shyu, C.R.; Chopra, S. A sorghum MYB transcription factor induces 3-deoxyanthocyanidins and enhances resistance against leaf blights in maize. Molecules 2015, 20, 2388-2404. [CrossRef]

131. Nakatsuka, T.; Nishihara, M. UDP-glucose:3-deoxyanthocyanidin 5-O-glucosyltransferase from Sinningia cardinalis. Planta 2010, 232, 383-392. [CrossRef] [PubMed]

132. Yang, L.; Dykes, L.; Awika, J.M. Thermal stability of 3-deoxyanthocyanidin pigments. Food Chem. 2014, 160, 246-254. [CrossRef] [PubMed]

133. Xiong, Y.; Zhang, P.; Warner, R.D.; Fang, Z. 3-Deoxyanthocyanidin Colorant: Nature, Health, Synthesis, and Food Applications. Compr. Rev. Food Sci. Food Saf. 2019, 18, 1533-1549. [CrossRef] [PubMed]

134. Petti, C.; Kushwaha, R.; Tateno, M.; Harman-Ware, A.E.; Crocker, M.; Awika, J.; Debolt, S. Mutagenesis breeding for increased 3-deoxyanthocyanidin accumulation in leaves of Sorghum bicolor (L.) Moench: A source of natural food pigment. J. Agric. Food Chem. 2014, 62, 1227-1232. [CrossRef] [PubMed]

135. Lepiniec, L.; Debeaujon, I.; Routaboul, J.M.; Baudry, A.; Pourcel, L.; Nesi, N.; Caboche, M. Genetics and biochemistry of seed flavonoids. Annu. Rev. Plant Biol. 2006, 57, 405-430. [CrossRef]

136. Martens, S.; Preuss, A.; Matern, U. Multifunctional flavonoid dioxygenases: Flavonol and anthocyanin biosynthesis in Arabidopsis thaliana L. Phytochemistry 2010, 71, 1040-1049. [CrossRef]

137. Wang, P.; Zhang, L.; Jiang, X.; Dai, X.; Xu, L.; Li, T.; Xing, D.; Li, Y.; Li, M.; Gao, L.; et al. Evolutionary and functional characterization of leucoanthocyanidin reductases from Camellia sinensis. Planta 2018, 247, 139-154. [CrossRef] [PubMed]

138. Katsu, K.; Suzuki, R.; Tsuchiya, W.; Inagaki, N.; Yamazaki, T.; Hisano, T.; Yasui, Y.; Komori, T.; Koshio, M.; Kubota, S.; et al. A new buckwheat dihydroflavonol 4-reductase (DFR), with a unique substrate binding structure, has altered substrate specificity. BMC Plant Biol. 2017, 17, 239. [CrossRef]

139. Jun, J.H.; Xiao, X.; Rao, X.; Dixon, R.A. Proanthocyanidin subunit composition determined by functionally diverged dioxygenases. Nature Plants 2018, 4, 1034-1043. [CrossRef] [PubMed]

140. Henry-Kirk, R.A.; McGhie, T.K.; Andre, C.M.; Hellens, R.P.; Allan, A.C. Transcriptional analysis of apple fruit proanthocyanidin biosynthesis. J. Exp. Bot. 2012, 63, 695-709. [CrossRef]

141. Dixon, R.A.; Xie, D.Y.; Sharma, S.B. Proanthocyanidins-a final frontier in flavonoid research? New Phytol. 2005, 165, 9-28. [CrossRef]

142. Su, Q.; Wang, S.; Sun, Y.; Mei, J.; Ke, L. Advances in Biosynthesis and Regulation of Plant Proanthocyanidins. Chin. J. Cell Biol. 2021, 43, 219-229.

143. Yuan, L.; Wang, L.; Han, Z.; Jiang, Y.; Zhao, L.; Liu, H.; Yang, L.; Luo, K. Molecular cloning and characterization of PtrLAR3, a gene encoding leucoanthocyanidin reductase from Populus trichocarpa, and its constitutive expression enhances fungal resistance in transgenic plants. J. Exp. Bot. 2012, 63, 2513-2524. [CrossRef]

144. Dong, W.; Ma, H.; Chen, C.; Li, Y. Overexpression of the OvBAN gene enhances the proanthocyanidin content in transgenic alfalfa (Medicago sativa L.). In Vitr. Cell. Dev. Biol.-Plant 2020, 56, 548-557. [CrossRef]

145. Xin, Y.; Meng, S.; Ma, B.; He, W.; He, N. Mulberry genes MnANR and MnLAR confer transgenic plants with resistance to Botrytis cinerea. Plant Sci. 2020, 296, 110473. [CrossRef] [PubMed]

146. Xu, W.; Dubos, C.; Lepiniec, L. Transcriptional control of flavonoid biosynthesis by MYB-bHLH-WDR complexes. Trends Plant Sci. 2015, 20, 176-185. [CrossRef] [PubMed]

147. Dubos, C.; Stracke, R.; Grotewold, E.; Weisshaar, B.; Martin, C.; Lepiniec, L. MYB transcription factors in Arabidopsis. Trends Plant Sci. 2010, 15, 573-581. [CrossRef]

148. Cao, Y.; Jia, H.; Xing, M.; Jin, R.; Grierson, D.; Gao, Z.; Sun, C.; Chen, K.; Xu, C.; Li, X. Genome-Wide Analysis of MYB Gene Family in Chinese Bayberry (Morella rubra) and Identification of Members Regulating Flavonoid Biosynthesis. Front. Plant Sci. 2021, 12, 691384. [CrossRef]

149. Zhang, B.; Xu, X.; Huang, R.; Yang, S.; Li, M.; Guo, Y. CRISPR/Cas9-mediated targeted mutation reveals a role for AN4 rather than DPL in regulating venation formation in the corolla tube of Petunia hybrida. Hortic. Res. 2021, 8, 116. [CrossRef] 
150. Li, J.; Luan, Q.; Han, J.; Zhang, C.; Liu, M.; Ren, Z. CsMYB60 directly and indirectly activates structural genes to promote the biosynthesis of flavonols and proanthocyanidins in cucumber. Hortic. Res. 2020, 7, 103. [CrossRef] [PubMed]

151. Xu, H.; Yang, G.; Zhang, J.; Wang, Y.; Zhang, T.; Wang, N.; Jiang, S.; Zhang, Z.; Chen, X. Overexpression of a repressor MdMYB15L negatively regulates anthocyanin and cold tolerance in red-fleshed callus. Biochem. Biophys. Res. Commun. 2018, 500, 405-410. [CrossRef] [PubMed]

152. Li, C.; Qiu, J.; Ding, L.; Huang, M.; Huang, S.; Yang, G.; Yin, J. Anthocyanin biosynthesis regulation of DhMYB2 and DhbHLH1 in Dendrobium hybrids petals. Plant Physiol. Biochem. 2017, 112, 335-345. [CrossRef] [PubMed]

153. Totsuka, A.; Okamoto, E.; Miyahara, T.; Kouno, T.; Cano, E.A.; Sasaki, N.; Watanabe, A.; Tasaki, K.; Nishihara, M.; Ozeki, Y. Repressed expression of a gene for a basic helix-loop-helix protein causes a white flower phenotype in carnation. Breed. Sci. 2018, 68, 139-143. [CrossRef]

154. Gonzalez, A.; Zhao, M.; Leavitt, J.M.; Lloyd, A.M. Regulation of the anthocyanin biosynthetic pathway by the TTG1/bHLH/Myb transcriptional complex in Arabidopsis seedlings. Plant J. 2008, 53, 814-827. [CrossRef] [PubMed]

155. Gao, Y.; Liu, J.; Chen, Y.; Tang, H.; Wang, Y.; He, Y.; Ou, Y.; Sun, X.; Wang, S.; Yao, Y. Tomato SlAN11 regulates flavonoid biosynthesis and seed dormancy by interaction with bHLH proteins but not with MYB proteins. Hortic. Res. 2018, 5, 27. [CrossRef]

156. Ni, J.; Bai, S.; Zhao, Y.; Qian, M.; Tao, R.; Yin, L.; Gao, L.; Teng, Y. Ethylene response factors Pp4ERF24 and Pp12ERF96 regulate blue light-induced anthocyanin biosynthesis in 'Red Zaosu' pear fruits by interacting with MYB114. Plant Mol. Biol. 2019, 99, 67-78. [CrossRef] [PubMed]

157. Zhao, X.; Zeng, X.; Lin, N.; Yu, S.; Fernie, A.R.; Zhao, J. CsbZIP1-CsMYB12 mediates the production of bitter-tasting flavonols in tea plants (Camellia sinensis) through a coordinated activator-repressor network. Hortic. Res. 2021, 8, 110. [CrossRef]

158. Zhou, H.; Lin-Wang, K.; Wang, H.; Gu, C.; Dare, A.P.; Espley, R.V.; He, H.; Allan, A.C.; Han, Y. Molecular genetics of blood-fleshed peach reveals activation of anthocyanin biosynthesis by NAC transcription factors. Plant J. 2015, 82, 105-121. [CrossRef] [PubMed]

159. Li, C.; Wu, J.; Hu, K.D.; Wei, S.W.; Sun, H.Y.; Hu, L.Y.; Han, Z.; Yao, G.F.; Zhang, H. PyWRKY26 and PybHLH3 cotargeted the PyMYB114 promoter to regulate anthocyanin biosynthesis and transport in red-skinned pears. Hortic. Res. 2020, 7, 37. [CrossRef]

160. Ren, Y.R.; Zhao, Q.; Yang, Y.Y.; Zhang, T.E.; Wang, X.F.; You, C.X.; Hao, Y.J. The apple 14-3-3 protein MdGRF11 interacts with the BTB protein MdBT2 to regulate nitrate deficiency-induced anthocyanin accumulation. Hortic. Res. $2021,8,22$. [CrossRef] [PubMed]

161. Luo, D.; Xiong, C.; Lin, A.; Zhang, C.; Sun, W.; Zhang, J.; Yang, C.; Lu, Y.; Li, H.; Ye, Z.; et al. SlBBX20 interacts with the COP9 signalosome subunit SICSN5-2 to regulate anthocyanin biosynthesis by activating SIDFR expression in tomato. Hortic. Res. 2021, 8, 163. [CrossRef] [PubMed]

162. Wang, Y.; Wang, N.; Xu, H.; Jiang, S.; Fang, H.; Zhang, T.; Su, M.; Xu, L.; Zhang, Z.; Chen, X. Nitrogen Affects Anthocyanin Biosynthesis by Regulating MdLOB52 Downstream of MdARF19 in Callus Cultures of Red-Fleshed Apple (Malus sieversii f. niedzwetzkyana). J. Plant Growth Regul. 2017, 37, 719-729. [CrossRef]

163. Liang, T.; Shi, C.; Peng, Y.; Tan, H.; Xin, P.; Yang, Y.; Wang, F.; Li, X.; Chu, J.; Huang, J.; et al. Brassinosteroid-Activated BRI1-EMS-SUPPRESSOR 1 Inhibits Flavonoid Biosynthesis and Coordinates Growth and UV-B Stress Responses in Plants. Plant Cell 2020, 32, 3224-3239. [CrossRef] [PubMed]

164. Jiao, C.; Sorensen, I.; Sun, X.; Sun, H.; Behar, H.; Alseekh, S.; Philippe, G.; Palacio Lopez, K.; Sun, L.; Reed, R.; et al. The Penium margaritaceum Genome: Hallmarks of the Origins of Land Plants. Cell 2020, 181, 1097-1111. [CrossRef]

165. Lu, C.; Li, Y.; Cui, Y.; Ren, J.; Qi, F.; Qu, J.; Huang, H.; Dai, S. Isolation and Functional Analysis of Genes Involved in Polyacylated Anthocyanin Biosynthesis in Blue Senecio cruentus. Front. Plant Sci. 2021, 12, 640746. [CrossRef]

166. Noda, N.; Aida, R.; Kishimoto, S.; Ishiguro, K.; Fukuchi-Mizutani, M.; Tanaka, Y.; Ohmiya, A. Genetic engineering of novel bluer-colored chrysanthemums produced by accumulation of delphinidin-based anthocyanins. Plant Cell Physiol. 2013, 54, 1684-1695. [CrossRef]

167. Kallscheuer, N.; Vogt, M.; Bott, M.; Marienhagen, J. Functional expression of plant-derived O-methyltransferase, flavanone 3-hydroxylase, and flavonol synthase in Corynebacterium glutamicum for production of pterostilbene, kaempferol, and quercetin. J. Biotechnol. 2017, 258, 190-196. [CrossRef]

168. Lim, C.G.; Wong, L.; Bhan, N.; Dvora, H.; Xu, P.; Venkiteswaran, S.; Koffas, M.A. Development of a Recombinant Escherichia coli Strain for Overproduction of the Plant Pigment Anthocyanin. Appl. Environ. Microbiol. 2015, 81, 6276-6284. [CrossRef]

169. Zhang, F.; Guo, H.; Huang, J.; Yang, C.; Li, Y.; Wang, X.; Qu, L.; Liu, X.; Luo, J. A UV-B-responsive glycosyltransferase, OsUGT706C2, modulates flavonoid metabolism in rice. Sci. China Life Sci. 2020, 63, 1037-1052. [CrossRef] [PubMed]

170. Ye, Z.; Yu, J.; Yan, W.; Zhang, J.; Yang, D.; Yao, G.; Liu, Z.; Wu, Y.; Hou, X. Integrative iTRAQ-based proteomic and transcriptomic analysis reveals the accumulation patterns of key metabolites associated with oil quality during seed ripening of Camellia oleifera. Hortic. Res. 2021, 8, 157. [CrossRef] [PubMed] 